\title{
COOLANT MIXING IN SODIUM COOLED \\ FAST REACTOR FUEL BUNDLES
}

\section{WASH - 1096}

\author{
N. E. Todreas and L. W. Wilson \\ Division of Reactor Development and Technology \\ U. S. Atomic Energy Commission \\ Washington, D。C。
}

April 1968

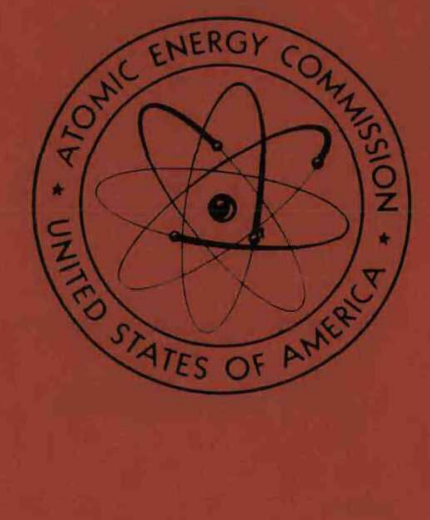

MASTER 


\section{DISCLAIMER}

This report was prepared as an account of work sponsored by an agency of the United States Government. Neither the United States Government nor any agency Thereof, nor any of their employees, makes any warranty, express or implied, or assumes any legal liability or responsibility for the accuracy, completeness, or usefulness of any information, apparatus, product, or process disclosed, or represents that its use would not infringe privately owned rights. Reference herein to any specific commercial product, process, or service by trade name, trademark, manufacturer, or otherwise does not necessarily constitute or imply its endorsement, recommendation, or favoring by the United States Government or any agency thereof. The views and opinions of authors expressed herein do not necessarily state or reflect those of the United States Government or any agency thereof. 


\section{DISCLAIMER}

Portions of this document may be illegible in electronic image products. Images are produced from the best available original document. 


\section{LEGAL NOTICE}

This book was prepared under the sponsorship of the U. S. Atomic Energy Commission. Neither the United States, nor the Commission, nor any person acting on behalf of the Commission:

A. Makes any warranty or representation, expressed or implied, with respect to the accuracy, completeness, or usefulness of the information contained in this publication or that the use of any information, apparatus, method, or process disclosed in this book may not infringe privately owned rights; or

B. Assumes any liabilities with respect to the use of, or for damages resulting from the use of any information, apparatus, method, or process disclosed in this publication.

As used in the above, "person acting on behalf of the Commission" includes any employee or contractor of the Commission, or employee of such contractor, to the extent that such employee or contractor of the Commission, or employee of such contractor prepares, disseminates, or provides access to, any information pursuant to his employment or contract with the Commission, or his employment with such contractor.

\section{Printed in the United States of America}

\section{Available from}

Clearinghouse for Federal Scientific and Technical Information

National Bureau of Standards, U. S. Department of Commerce

Springfield, Virginia 22151

Price: Printed Copy $\$ 3.00$; Microfiche $\$ 0.65$ 
WASH-1096

Reactor Technology - UC-80

COOLANT MIXING IN SODIUM COOLED

FAST REACTOR FUEL BUNDLES

N. E. Todreas and L. W. Wilson

Division of Reactor Development and Technology

U. S. Atomic Energy Commission

Washington, D. C.

Apri1, 1968

\section{Abstract}

Radial subchannel temperature imbalances can be quite severe in typical fast reactor designs of tight pitch to diameter ratios ( $p / d$ $\leq 1.20)$. Consideration of mixing between interconnected subchannels is required to avoid the significant design penalties which would otherwise be imposed. The available experimental data and analytic methods for predicting coolant mixing are presented and their deficiencles relative to sodium cooled fast reactor application discussed. Sodium conduction effects, subchannel area changes and forced mixing effects due to grid and wire wrap pin spacing techniques are the key fuel assembly characteristics which must be considered in conducting experiments and formulating analytic methods for fast reactor application.

\section{LEGAL NOTICE} This report was prepered as an account of Covernment spolf of the Commisston Thates A. Makes any warranty or representauton, expres contained in this report, or that the use

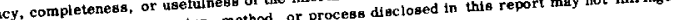
of any information, apparatus, method, or proces dis privately owned rights; or

B. Assumes any liabilites was, method, or process disclosed in this report, As ured tn the above, "person acting on behalf of the Commisason" As used in the of the Corminssion, or employoe employee of such contractor prepares, 


\section{ACKNOWLEDGMENT}

The authors wish to express their appreciation to the following individuals for their assistance in bringing the authors attention to analytic and experimental mixing programs already completed or currently in progress: G. D. McPherson, J. H. Field, J. T. Rogers, D. S. Rowe,

J. Yatabe, J. M. Batch, A. A. Bishop, F. A. Schraub, J. Casterline, and R. M. Scroggins. 
TABLE OF CONTENTS

$\underline{\text { Page }}$

ACKANOWLEDGEMENT • . . . . . . . . . . . . . . . . . ii

momenclatuRE ......................... v

INTRODUCTION . . . . . . . . . . . . . . . . . 1

EFFECTS OF MIXING IN THE FUEL DESIGN OF LIQUID METAL . . . . 4

Fast Breeder Reactors ...... . . . . . . . 4

Cladding Hot Spot Limits . . . . . . . . . . . . 5

Subassembly Flow Housing Bowing and Deformation . . . . . 8

Subchannel Flow Blockage . . . . . . . . . . . . 9

Location of Subassembly Outlet Instrumentation . . . . . . 10

DEFIUITION OF MIXING EFFECTS . . . . . . . . . . . . . 11

AVAILABLE DATA AND PROPOSED CORRELATIONS . . . . . . . . 13

Subchannel Definition . . . . . . . . . . . . . . 14

Deta and Correlations for Natural Mixing . . . . . . . 15

Turbulent Interchange . . . . . . . . . . . 15

Diversion Cross-Flow . . . . . . . . . . . . 22

Data and Correlations for Forced Mixing . . . . . . . . 23

AVAILABLE CODES FOR SUBCHANNEL ANALYS IS . . • . . . . • . 29

Codes Which Consider Turbulent Interchange Only . . . . . 30

Codes Which Consider Diversion Cross-Flow Only . . . . . . 31

Codes Which Consider Flow Sweeping Only . . . . . . . . 32

Codes Which Cover Several Mixing Effects . . . . . . . . 33

DEVELOPMENT OF TECHNIQUES FOR LIQUID METAL APPLICATION • • • • 38

CURRENT MIXING STUDIES IN PROGRESS . . . . . . . . . . . . 42

TABLE I - Subassembly Geometries Typheal of Liquid Metal

Fast Breeder Reactor and U.S. Fast Reactor Designs . . . . 51

TABLE II - Summary of Some Experimental Programs Since

Moyer's Report .................... . 52 
TABLE OF CONTENTS (Cont'd)

Page

TABLE III - Codes for Subchannel Analysis . . . . . . 54

TABLE IV - Subassembly Geometries Typical of Liquid

Metal Fast Breeder Reactors, Heavy Water, and Light

Water Reactor Designs . . . . . . . . . . 55

TABLE V - Mixing Studies - Proposed or in Progress

Part A - For Water Cooled Reactor Application

Part B - For Liquid Metal Cooled Reactor Application. - 56

FIGURE 1 - Cross-Section of Typica1 19 Element

Bundles in Circular and Hexagonal Flow Ducts . . . . 59

FIGURE 2 - Effect of Natural Mixing on Coolant

Temperature Distribution Across a Tightly Packed

217 Pin Bundle . . . . . . . . . . . . 60

FIGURE 3 - Effect of Natural Mixing on Coolant

Temperatures for Pin Misalignment in a Tightly

Packed Bundle... . . . . . . . . . . 61

FIGURE 4 - Cross-Section of Two Connected Sub-

channels in a Triangular Array . . . . . . . . 62

REFERENCES . . . . . . . . . . . . . 63 
NOMENCLATURE

$A_{i}=$ flow area of $i$ 'th subchannel, $f t^{2}$.

$A_{f i}=$ area swept by fin or wire wrap spacer in $i^{\prime}$ th subchanne1, ft.

$b_{i}=$ wetted perimeter of $i^{\prime}$ th subchannel, ft.

c = Spacing between rods, $\mathrm{ft}$.

$\mathrm{d} \quad=$ diameter of rod, ft.

$d_{e_{i}}=$ equivalent diameter of subchannel, ft.

f $\quad$ friction factor.

$G_{i}=$ average axial mass flux in $i^{\prime}$ th subchannel, $1 \mathrm{~b} / \mathrm{ft}^{2}-\mathrm{hr}$.

$h_{i j}=$ enthalpy difference between subchannels $i$ and $j, B T U / 1 b . m$.

$\mathrm{K}_{\mathrm{g}} \quad=$ constant.

$M_{i j}$ = effective mixing Stanton Number (Reference 12 and 20).

p = axial pitch of helix of wire wrap or fin spacers.

$q^{\prime}{ }_{i j}=$ turbulent heat transport per unit length, BTU/hr.ft.

$u_{i}=$ axial flow velocity in $i^{\prime}$ th subchannel, $\mathrm{ft} / \mathrm{sec}$.

$\mathrm{W}_{\mathbf{i}} \quad=$ axial mass flow rate, $1 \mathrm{~b} / \mathrm{hr}$.

$w_{i j}=$ diversion cross-flow rate per unit length, $1 \mathrm{~b} / \mathrm{hr}-\mathrm{ft}$.

$w^{\prime}{ }_{i j}=\begin{aligned} & \text { effective magnitude of turbulent interchange per unit length, } \\ & 1 \mathrm{~b} / \mathrm{hr}-\mathrm{ft} .\end{aligned}$

$z_{i j}=$ effective lateral distance between subchannels, ft.

$6_{M} \quad=$ eddy diffusivity of momentum.

$\epsilon_{\mathrm{H}} \quad=$ eddy diffusivity of heat.

$\nu \quad=$ kinematic viscosity.

$\theta \quad=$ angle subtended at pin center by subchannel boundaries. 
NOMENCLATURE (Continued)

$\boldsymbol{\nabla}=$ peripheral distance between fins or wires on one rod, ft.

$\rho=$ density, $1 \mathrm{~b} \cdot \mathrm{m} / \mathrm{ft} .^{3}$

$\boldsymbol{\beta}=$ effective mixing stanton Number called turbulent mixing parameter in Reference 13, dimensionless.

$\bar{\Psi} \quad=$ ratio of eddy diffusivity of heat to eddy diffusivity of momentum, $G_{\mathrm{H}} / G_{\mathrm{M}}$ 


\section{INTRODUCTION}

Present light water power reactor and proposed Liquid Metal Cooled Fast Breeder Reactor (LMFBR) fuel element bundles consist of a parallel matrix of rods forming interconnected subchannels. Generally, reactor thermal analysis has recognized but not quantitatively accounted for the interchange or mixing of coolant between the bundle subchannels. While coolant interchange in bare and mechanically supported rod bundles has been investigated over the last ten to fifteen years, only during the last five years have effective analytic models for evaluating these effects been formulated and applied in design.

The surveys of Coates ${ }^{(1)^{1}}$ and Moyer ${ }^{(2)}$ summarize, as of 1960 and 1964 respectively, the available experimental data and analytic models which almost exclusively relate to water coolant experience. The highlights of Moyer's survey plus the significant additions to the literature since this review are summarized in this paper together with specific reference to the relevance and application of this available technology to liquid metal fast breeder reactor systems.

Transverse coolant mixing between interconnecting subchannels in a general axial coolant flow situation can be considered to be the result of four effects, presented in the following table. Conduction effects also can act to affect subchannel thermal conditions, particularly in 1. Numbers in brackets designate References at end of paper. 
sodium systems. The effects of this molecular conduction will be considered in the later discussion.

\begin{tabular}{ccc}
\hline & Natural Mixing Effects & Forced Mixing Effects \\
\hline $\begin{array}{c}\text { Non-Directional } \\
\text { Flow Effects }\end{array}$ & Turbulent Interchange & Flow Scattering \\
$\begin{array}{c}\text { Directional } \\
\text { Flow Effects }\end{array}$ & Diversion Cross-flow & Flow Sweeping \\
\hline
\end{tabular}

"Natural" mixing effects include those processes which are operable in the absence of external perturbations in the rod bundles, i.e., a bundle of smooth, bare rods. Turbulent interchange results from natural eddy diffusion between subchannels and diversion cross-flow is the directed cross-flow mixing which is caused by radial pressure gradients between adjacent subchannels. These gradients may be induced by gross differences between the subchannel geometries, heat flux distributions, pin eccentricity or bowing, and can also be caused by changes in equivalent diameter of the flow duct or bunde eccentricity within the flow duct. Figure 1 shows the varying subchannel arrangements for typical 19-rod test bundles arrayed to fit circular and hexagonal flow ducts. It appears that the effects of diversion cross-flow are only significant for (1) the entrance length of the channels because of flow redistribution caused by the above effects; (2) locations of abrupt change of flow area due to pin bowing or subchannel blockage or due to fuel bundle design choice. An example of the latter occurs in the Fast Flux Test Facility 
(FFTF) dispersed core concept, where a transition in the flow duct from hexagonal to circular cross section is provided just above the active core region to minimize pressure drop; and (3) where the asymmetries described above may cause one subchannel to boil sooner than an adjacent one, and the resulting variation in void fraction and coolant properties between subchannels induces significant diversion cross-flow. Some authors have previously used the term "natural mixing" to describe turbulent interchange only, and diversion cross-flow has some times been referred to as "forced mixing;" however, the above definition of natural mixing which includes both turbulent and diversion mixing seems reasonable in order to restrict the term "forced mixing" to effects which are induced by mechanical perturbations in the flow channe1. These perturbations can be pin spacers or support structures which serve simply to break up the flow in a random fashion in which case the designation "flow scattering" is applied. Alternately, the perturbations may be spacers such as wire wraps, helical fins, contoured grids or mixing vanes which divert a part of the flow in a preferred direction. This type of spacer action has been designated as "flow sweeping." Since these forced mixing effects are directly related to the associated pressure drop, the design problem is to reconcile the two conflicting goals of best possible mixing behavior at the least possible pressure drop. 
EFFECTS OF MIXING IN THE FUEL DESIGN OF LIQUID METAL

\section{Fast Breeder Reactors}

In both water and liquid metal reactor application, the study of coolant mixing in rod bundles is aimed at determining the local coolant properties within individual subchannels. Specific properties of interest are coolant flow rate and enthalpy. Water reactor interest in local subchannel property definition centers on the problem of critical heat flux prediction. Significant improvements in correlation of experimental critical heat flux data from rod bundles should be possible by considering the local coolant and heat flux conditions at the observed critical location rather than bundle average conditions. In fact, two comprehensive computer techniques for subchannel analysis, HAMBO ${ }^{(3)}$, and THINC-II ${ }^{(4)}$, include subroutines for prediction of critical heat flux ratios based on local subchannel conditions and incorporate critical heat flux correlations.

For the steady state, single-phase operating conditions of liquid metal fast breeder reactors, mixing phenomenon are potentially significant for designing to limits in the following areas:

1. Cladding hot spot

2. Subassembly flow housing bowing and deformation

3. Subchannel flow blockages

4. Location of subassembly outlet instrumentation. 
During overpower or loss of flow transients, bulk coolant temperatures can approach and exceed the saturation condition. Although these reactors normally operate with significant subcooling, because of the local positive sodium void characteristic of these reactors and the presently unassessed void growth behavior in the forced convection mode, the prediction of incipient vaporization is an important goal. Design application of a satisfactory formulation, when developed, will also require accurate knowledge of local subchannel conditions and hence consideration of mixing phenomena. With the present lack of knowledge of consequences of incipient nucleation, a design criteria is maintenance of bulk sodium coolant temperature below saturation. Since the predominant parameter in assessing design conditions relative to this limit, the hot channel factor $\mathrm{F}_{\mathbf{A H}}$, is also an operative factor relative to the cladding hot spot limit, the discussion of design problems will focus on the above listed areas. This discussion will be based on subassembly geometries typical of sodium cooled, fast spectrum test and demonstration breeder reactor designs summarized in Table I. Table I also lists the characteristics of the existing U.S. sodium cooled fast spectrum reactors for comparison purposes.

Cladding Hot Spot Limits

The successful operation of the proposed mixed oxide fuel elements to design burnup goals is sensitive to the maintenance of clad temperatures below established hot spot limits. In the $1100-1300^{\circ} \mathrm{F}$ temperature 
range of interest, clad strength, ductility and corrosion are sensitive to small changes in hot spot temperature. Since core thermal performance is adversely affected proportional to the temperature difference between the nominal clad temperature and the hot spot limit, it is highly desirable to minimize this delta,temperature and the associated uncertainties in its prediction. Accurate prediction of clad temperatures is also desirable to permit interpretation of fuel pin irradiation data.

The factors affecting this temperature difference can be conveniently summarized in terms of gross subchannel effects and detailed flow and geometry description within the subchannel. The first or so called gross effect is generally characterized in terms of a hot channel factor for coolant temperature and film temperature differences between bundle subchannels. These differences derive both from subchannel geometries variations between bundle edge subchannels and central bundle subchannels - which induce varying gross subchannel velocities and from radial power distributions. For typically packed arrays of pitch to diameter ratio $(\mathrm{p} / \mathrm{d})$ equaling 1.2 , peaking factors of 1.15 applied to the total coolant delta $T$ through the core can arise. Thus, the local bulk coolant temperature associated with a pin in the center of the bundle can be nearly $50^{\circ} \mathrm{F}$ higher than the average bulk coolant temperature for a core temperature rise of $300^{\circ} \mathrm{F}$. This higher coolant exit temperature is directly reflected in the peak clad temperature since this normally occurs at the core exit in these sodium cooled systems. For closer packed triangular 
arrays, subchannel temperature imbalances calculated assuming no mixing are even more severe. Figure 2 illustrates the temperature distribution across a 217-pin subassembly operating at an average 1inear power of 9.7 $\mathrm{kw} / \mathrm{ft}$ having $\mathrm{p} / \mathrm{d}=1.12$ at the end of the 32 -inch long fuel section ${ }^{(7)}$, and radial power variation of 1.17 Peak/Average. Only natural mixing effects are considered.

The second effect concerns local perturbations associated with and adjacent to each pin. These perturbations manifest themselves in circumferential temperature variations in the cladding. The perturbation within the pin can result from postulated fuel pellet stackings leading to eccentric gas gaps and from non-ovality of the pin cladding. These effects have been recently assessed by Grillo and Testa ${ }^{(8)}$. The perturbations adjacent to the pin of both flow and geometry results in a variation in heat removal capacity in the $\theta$ direction. This effect can be assessed using analytic techniques ${ }^{(9)}$ which predict velocity profiles within subchannels and apply these to clad temperature prediction through assumed eddy diffusivity values. For wire wrapped pins in triangular lattices at $\mathrm{p} / \mathrm{d}$ of 1.2 , these techniques predict possible pin circumferential temperature variations in the cladding of $30-60^{\circ} \mathrm{F}$ depending on axial flow Reynolds number ${ }^{(10)}$.

Both these gross and local effects can be further amplified by the consideration of stackup of fabrication tolerances in pins, spacers, and channel walls. In addition, significant subchannel flow area variations 
can result from pin distortion due to swelling as a function of burnup and pin bowing induced by circumferential temperature variations. Peripheral pins which are bounded by subchannels of significant geometric variation are particularly subject to bowing.

The effect of mixing on both these gross and local contributions to maximum clad temperature can be profound. Mixing always acts to homogenize the temperature imbalance between bundle subchannels and may have a significant effect on subchannel local velocity profiles through diversion cross-flows and forced mixing effects. Subassembly Flow Housing Bowing and Deformation

In addition to individual pin bowing, radial power distributions across a subassembly cause differences between the bulk fluid temperatures contacting the flow housing walls. The length of duct wall over which these temperature differences can persist is significant for the present LMFBR designs which favor outlet fission gas collection plenums. Allowing for a three-foot gas plenum and two-foot instrumentation package, five feet of duct length can exist from the end of the fuel to the flow outlet ports. Provision for axial reflector or blanket can increase this length further. For the tightly packed case of pitch to diameter ratio of 1.12 and a $350^{\circ} \mathrm{F}$ core temperature rise, $100^{\circ} \mathrm{F}$ differences between opposite duct surfaces can result. The consequent duct bowing is significant and in fast reactors which are neutronically sensitive to relatively sma11 degrees of fuel movement, this bowing must be considered. 
Again, coolant mixing effects tend to minimize the temperature differences. However, since this governing temperature differential is between subchannels on opposite sides of the flow duct, mixing cannot be expected to be a significant factor in reducing this difference. Correction of this imbalance dictates reduction in channel by-pass flow by partial blockage of outer subchannels, increase in $\mathrm{p} / \mathrm{d}$ to reduce the imbalance between outer and inner subchannel geometries, and/or flattening of the radial power distribution.

Subchanne1 Flow Blockage (Due to Foreign Objects or Pin Misalignment)

For the tightly packed bundles of interest, considerable attention is being directed to the consequences of varying amounts of subchanne1 blockage and the detection of such blockages. Obviously, the consequences of flow blockages in terms of subchannel temperature excursions downstream of the blockage are very sensitive to the assumptions of coolant mixing. The effect of such mixing is twofold; first, in mitigating the resultant excursion by mixing cooler fluid from adjacent subchannels into the blocked subchannel(s), and second, by eliminating channeling effects and the existance of a high temperature plume at the channel exit of the subchanne1(s) which were assumed blocked. Since it is impractical to locate numerous thermocouples within a subassembly to detect such plumes for blockages in arbitrary locations, we conclude that while mixing does not assist in detection of the occurrence of flow blockages, it can materially assist in reducing the severity of the consequences of such a blockage. 
These considerations are summarized in Figure $3^{(7)}$ which illustrates that for a reduction of pin spacing to $25 \%$ of normal value for the bundle of Figure 2 operating at an average 1inear power of $13.6 \mathrm{kw} / \mathrm{ft}$, the temperature rise to $1752^{\circ} \mathrm{F}$ leading to pin failure for a no-mixing assumption is reduced to an acceptable $1050^{\circ} \mathrm{F}$ for a moderate degree of assumed natural mixing. In this case, the misalignment was assumed due to movement of three pins toward the center of their common subchannel over the entire core length. However, note that mixing over the plenum gas region tends to minimize the resultant subchannel temperature at the thermocouple plane beyond the gas plenum region. In cases of a local blockage or pin misalignment, a length of clad could exceed the hot spot limit but go undetected by the instrumentation at the subassembly outlet. Location of Subassembly outlet Instrumentation

Since a temperature gradient exists in liquid metal pipe flows across the entire flow channel compared to a relatively flat profile for fully developed high ( $\operatorname{Pr} \cong 1$ ) Prandlt number flows, the determination of representative outlet bulk temperatures is sensitive to instrument location. This difficulty can be easily corrected if pressure head is available to permit preparation of a well-mixed sample. However, with the present head limitations of state-of-the-art main coolant pumps and the large core pressure drops associated with the need to provide significant lengths of fission gas plenum, such pressure head margin is not readily 
available. In this case, mixing effects can be beneficial in promoting effective flattening of outlet subassembly temperature profile at the thermocouple plane.

\section{DEFINITION OF MIXING EFFECTS}

In analyzing the effect of mixing on rod bundle temperature and pressure gradients, it has generally been assumed that the mixing process is the effect of a number of separable components which can be treated independently; some of which may be neglected for calculational simplicity if it may be demonstrated that their effects will be overshadowed by other effects in a particular situation. These four mixing processes, as outlined in the Introduction, are:

1. Natural Mixing Effects, operable in axial flow bundles of bare rods.

a. Turbulent Interchange, resulting from interfacial shear stress at subchannel boundaries; measured by turbulent eddy diffusivity of momentum, $\epsilon_{M^{*}}$. The effect of turbulent interchange on energy transfer is measured by the eddy diffusivity of heat, $\epsilon_{H}$, which in general has a different value from $6_{\mathrm{M}}$. The distinguishing feature of turbulent interchange is that its time-averaged magnitude at any subchannel boundary is always zero. That is, between subchannel $i$ and $j, w^{\prime}{ }_{i j}=-w^{\prime}{ }_{j i}$.

b. Diversion Cross-flow, is the directed flow which is driven by radial pressure gradients which may be present owing to any of 
the indicated number of asymmetric characteristics between subchannels $i$ and $j$. The analysis of diversion cross-flow is governed by the condition that the mass cross-flow rate into any subchannel is equal to the mass cross-flow rate out of it, or; for the $i^{\prime}$ th subchannel,

$$
\sum_{j} w_{i j}=-\sum_{j} w_{j i}
$$

This is obviously more general than the turbulent interchange condition which requires zero net flow across each boundary of a subchannel. This condition for diversion cross-flow admits to the possibility--indeed, considers the physical fact--of a net flow from the $i^{\prime}$ th to a $j^{\prime}$ th subchannel at their common boundary. This non-zero flow, in fact, is the fundamental physical difference between diversion and turbulent mixing. The diversion crossflow rate, $w_{i k}$, is a real physical flow, while $w^{\prime}{ }_{i j}$ is a semifictitious quantity which denotes the effective magnitude of turbulent interchange, rather than some specific measurable flow rate. In practice, the value of $w^{\prime}{ }_{i j}$ is deduced from measurements of subchannel enthalpy distribution, as the amount of lateral flow which, according to some model, would have caused the observed conditions.

2. Forced Mixing, is that subchannel interchange which is induced by the presence of pin spacers or grids in the flow channel. 
a. Flow Scattering, refers to the non-directional mixing effects associated with grid spacers, end plates and axial or circumferential fins, which break up streamlines and induce turbulence, but do not favor a single direction. Analysis of the effects of flow scattering is analogous to the effects of turbulent interchange, and in fact several existing models simply increase the value of the turbulent mixing parameter by some empirical or intuitive amount to allow for the effects of flow scattering.

b. Flow Sweeping, refers to the directed cross-flow effects associated with wire wrap spacers, helical fins, contoured grids and mixing vanes which give a net cross-flow in a preferred direction. Flow sweeping effects are thus analogous to diversion cross-flow effects in that they are the result of a directed driving force rather than a random flow perturbation.

\section{AVAILABLE DATA AND PROPOSED CORRELATIONS}

The first subchannel analyses simply divided the rod bundle into a number of individual but isolated parallel subchannels. Flow and enthalpy rise were calculated from the criterion that the pressure drop across each subchannel should be the same; i.e., the mixed flow model. In essence, none of the mixing effects which operate within communicating subchannels were explicitly considered. Examples of this type of subchannel analysis are Winfrith's LIFEBUOY ${ }^{(3)}$ and AECL's SUBCHAN ${ }^{(11)}$ methods. 
Subchannel Definition

Subsequent subchannel analyses have considered the distinct subchannels within the rod bundle and the interconnection between subchannels. Typically, the area is divided into a discrete number of subchannels radially, and into a number of incremental axial segments or nodes. Each node of each subchannel receives heat input from the fuel rod surfaces which compose its perimeter. Thus, a radial and axial heat flux profile may be considered by assigning a power rating to each surface bounding each node of each subchannel. Variation in power or fluid properties within a subchannel or along a surface circumferentially within a node are universally neglected. This approach is commonly called "the lumped parameter approach." Subchannel parameters are calculated in the same approximate fashion by solution of the equations of continuity, momentum and energy yielding a single value of temperature, pressure, flow rate, and quality (for two-phase models) for each node of each subchannel. Detailed property value variations within the node, both axially and radially, are universally neglected.

In considering mixing between two subchannels, the models assume that the fluid characteristic of channel I is transported from point $i$. to point $j$, a distance $z_{i j}$ as shown in Figure 4 . Points $i$ and $j$ are taken as centroids of subchannels $I$ and $J$, respectively. The magnitude of the mixing effect is assumed to be inversely proportional to the distance between centroids, $z_{i j}$. The lateral resistance is taken inversely 
proportional to the throat width, c, so the magnitude of mixing is assumed directly proportional to $c$. Thus, the geometrical factor $c / z_{i j}$ is present in the models as a factor multiplying the turbulent interchange rate. The assumptions cited, of course, are not entirely accurate since much of the turbulent interchange takes place between points separated by a distance less than $z_{i j}$, while much of the forced mixing due to wire wrap, for example, occurs between points like $e$ and $f$, around the curvature of the rod. In that case, the effective mixing distance is actually greater than $z_{i j}$. Thus, the description of the geometry and the factors which govern the enthalpy actually transported across subchannel boundaries are more detailed than the assumed lumped parameter approach allows.

\section{Data and Correlations for Natural Mixing}

\section{Turbulent Interchange}

The effect of turbulent interchange between adjacent subchannels on the nodal enthalpies is characterized by a turbulent transverse heat flow rate which is equal to an effective transverse flow rate $w^{\prime}{ }_{i j}$ multiplied by the enthalpy difference between subchannels. Hence, the turbulent heat transport per unit length between channels $i$ and $j$ is given by

$$
q_{i j}^{\prime}=w_{i j}^{\prime}\left(d h_{i j}\right)=\bar{\rho}_{i j} c \bar{\sigma}_{M_{i j}}\left(\frac{d h}{d z_{i j}}\right)
$$

Since the eddy diffusivity of momentum is expressible as

$$
\frac{6}{\nu}=K \bar{R} e^{t+1}
$$


where $K$ and $t$ are constants, we obtain the following expression for transverse flow rate per unit length

$$
w_{i j}^{\prime}=k \frac{c \bar{\mu}_{i}}{z_{i j}} \overline{R e}^{t+1}
$$

Rearranging this expression utilizing a portion of the Reynolds number to eliminate $\mu$ as suggested by the constant $t+1$, we obtain

$$
w_{i j}^{\prime}=k \frac{c \bar{G}_{i} d_{e_{i}}}{z_{i j}} \overline{R e}
$$

Since $w^{\prime}{ }_{i j}$ is the effective transverse flow rate per unit axial length, and $c$ is the circumferential width of the subchannel boundary, it is seen that $\left(w_{i j} / d\right)$ is the effective transverse mass flux across the subchannel boundary. Since $G_{i}$ is the axial mass flux, a convenient dimensionless parameter suggests itself;

$$
\frac{\text { Transverse Mass Flux }}{\text { Axial Mass Flux }}=\frac{w^{\prime}}{c G_{i j}}=M_{i j}
$$

By analogy with turbulent convection analysis, this dimensionless parameter is frequently called the mixing Stanton number. It is denoted as $M_{i j}$ by Rogers ${ }^{(12)}$, and as $\beta$ by Rowe ${ }^{(13)}$. In this form, the general turbulent mixing equation is thus

$$
M_{i j}=k\left(\frac{e_{i}}{z_{i j}}\right) \operatorname{Re} t
$$

Now, $\mathrm{K}$ and $\mathrm{t}$ are constants which are to be determined by analysis of data. 
Various authors have developed correlations for turbulent interchange and then applied experimental data to evaluate the constants. These correlations are different in appearance, but upon closer inspection, it may be seen that they are all equivalent in substance to Equation (5).

For example, Moyer develops a correlation based on the following form for turbulent mixing rate;

$$
\frac{w_{i j}^{\prime}}{w_{i}}=\frac{\rho_{6}\left(\frac{c}{z_{i j}}\right)}{w_{i}}
$$

which is developed from his conservation equations. The value of 6 which is employed results from analysis of the Nikuradse universal velocity profile at the center of a circular tube in fully developed turbulent flow;

$$
\frac{6}{r}=\frac{R e}{20} \sqrt{\frac{f}{2}}
$$

The Reynolds number for this case is defined in terms of the subchannel wetted perimeter,

$$
\operatorname{Re}=\frac{4 \mathrm{w}_{i}}{\mu b_{i}}
$$

Combining Equations (6) through (8) yields

$$
\frac{w^{\prime}{ }_{i j}}{w_{i}}=\frac{2 \sqrt{2}}{20} \sqrt{f} \frac{c}{z_{i j} b_{i}}
$$


Employing the common friction factor correlation $f=a e^{b}$, multiplying by $A_{i} / c$, noting that $\left(A_{i} / b_{i}\right)=\left(d_{e_{i}} / 4\right)$, Moyer's correlation transforms to;

$$
M_{i j}=\left(\frac{\sqrt{2 a}}{40}\right)\left(\frac{d_{e_{i}}}{z_{i j}}\right) R e^{b / 2}
$$

which is equivalent to Equation (3)

Moyer considers the data from five sources (14-18), predicting the turbulent flow rate from Equation (9) and comparing to the observed mixing. Satisfactory agreement is not achieved, although it is found that the discrepancy between predicted and observed mixing seems to decrease with the magnitude of the mixing. Moyer concludes that the uncertainties in the data are probably great enough to account for the lack of agreement. Rowe ${ }^{(19)}$ has also developed a correlation for turbulent interchange and has carried out a series of experiments to determine the constants. Using the friction factor correlation cited above, Rowe develops the following expression for $\epsilon_{\mathrm{H}}$ :

$$
\frac{6_{H}}{u_{i} d_{e_{i}}}=K \operatorname{Re}^{b / 2}
$$

Applying this to Equation (1) and defining $\beta$ by the expression $\mathrm{w}^{\prime}{ }_{\mathbf{i j}}=$ $\beta \rho c u$, Rowe develops the following correlation;

$$
\beta=k\left(\frac{{ }^{d} e_{i}}{z_{i j}}\right) R e^{b / 2}
$$


which again is identical to Equation (5) noting that $\beta$ is equivalent to $M_{i j}$.

By means of calculations using the COBRA code, Rowe and Angle determines the values of $M_{i j}$ which give closest agreement with the results of his experiments. He then uses these values to determine the appropriate values of $\mathrm{K}$ and $\mathrm{b}$. The pertinent geometrical and thermal hydraulic characteristics of Rowe and Angle's experiments are described in Table II. Rogers ${ }^{(20)}$ has very recently developed an additional correlation for turbulent interchange--a modification of the earlier correlation, which he developed in $1966^{(12)}$. The key assumption in Rogers' correlation is that the mixing distance $z_{i j}$ may be treated as a function which is proportional directly to gap spacing, and inversely to pin diameter, as is intuitively suggested by examination of Figure 4 . Rogers assumes the following dependence of $z_{i j}$.

$$
\frac{z_{i j}}{d}=K_{g}\left(\frac{c}{d}\right)^{r}
$$

He assumes the following correlation for $6_{M}$;

$$
\frac{G_{M}}{V}=K \operatorname{Re} e_{\text {ave }}^{\mathrm{m}}
$$

These two assumptions lead to the development of the following correlation;

$$
\lambda_{i j}=\frac{2 M_{i j} R e^{1-m}}{\left[1+\left(\frac{d_{e}}{d_{e_{i}}}\right)^{\frac{3 m}{2-n}}\right]\left(\frac{d_{i}}{d}\right)}=k\left(\frac{c}{d}\right)^{-r}
$$


where $\mathrm{n}$ is the Reynolds number exponent in the friction factor correlation, taken as 0.2 .

This equation may be rewritten as;

$$
M_{i j}=\left(\frac{K}{2}\left[1+\left(\frac{d_{j}}{d_{i}}\right)^{\frac{3 m}{2-n}}\right]\right)\left(\frac{d_{i}}{d\left(\frac{c}{d}\right)^{r}}\right) R e^{m-1}
$$

which in light of Equation (9) is the same as

$$
M_{i j}=\left[\frac{K K_{g}}{2}\left(1+\left(\frac{d_{j}}{d_{e_{i}}}\right)^{\frac{3 m}{2-n}}\right)\right]\left(\frac{d_{i}}{z_{i j}}\right) R e^{m-1}
$$

Equation (12) is seen to be equivalent to Equation (5) also, where the proportionality constant includes consideration of possible difference between the equivalent diameters of the two adjacent subchannels--an added refinement.

Rogers considers the data presented in eight sources (12, 14, 16, $17,19,21,22$, and 23) and calculates the values of $\lambda_{i j}$ for each experiment from the results and Equation (15). Plotting the values of $\lambda_{i j}$ against $(\mathrm{c} / \mathrm{d})$ on a $\log -\log \mathrm{plot}$, he determines the values of $\mathrm{K}$ and $\mathrm{r}$ from the intercept and slope of the least squares fit. The values obtained give agreement with all experiments considered within $\pm 18.7 \%$. This is excellent agreement considering the numerous sources of data and the wide range of $\mathrm{c} / \mathrm{d}$ ratios present, from 0.0335 to 0.40 . Some discrepancy exists between Rogers and Rowe and Angle's correlations which has not yet 
been resolved. The significant geometrical and thermal hydraulic characteristics of the five test programs cited by Rogers which have been conducted since Moyer's report are summarized in Table II.

Table II also includes the following three additional sources which were not considered by Rogers. The work of Eifler and Nijsing (24) at Ispra employed a test section which mocks up two connected tricusp subchannels formed by rods 1.58" in diameter separated by gaps of .079", .158", and .236". The purpose of the experiments was to determine the velocity profiles within the mixing region near the throat between the subchannels and to determine the effects of rod spacing and Reynolds number on the intra-subchannel details of the flow distribution. Part I of this report treats the problem analytically, considering effects of eddy diffusion within the subchannel, but neglecting all interactions between adjacent subchannels. Although the experimental and analytic parts of this work were not addressed directly to mixing phenomena, it may be of significance if and when it becomes desirable to refine the lumped parameter subchannel approximation by taking into account the local details of intra-channel flow conditions and fluid properties.

The experimental program at Technological University of Eindhoven is quite an extensive study of heat transfer and fluid flow characteristics of pressurized water reactors. The experiments focus on the effect of mixing on burnout heat flux, and the influence of radial heat flux and 
void fraction gradients. Some of the experimental data obtained have been compared with calculations done with the HAMBO code at Winfrith. These tests utilized a test section composed of two square flow channels $2 \mathrm{~cm}$ on a side, connected through a $3 \mathrm{~mm}$ gap, which approximates a square lattice rod bundle with $0.67^{\prime \prime}$ diameter rods and a pitch to diameter ratio of 1.175 . The two channels were heated over $80 \%$ of their length with heat fluxes in the ratio $4 / 3$ between the two channels. Although some preliminary data have been reported, the program is not completed and no firm conclusions have yet been published.

An experimental program at UKAEA Windscale ${ }^{(26)}$ in support of the British gas-cooled reactor program, considered the effects of turbulent mixing; but the pin spacing is so wide in these designs, and the test bundle configuration is so different from that of the typical LMFBR design, that the data obtained are of little value direct to the liquid metal program. Also, with pitch to diameter ratios in the range 1.3-2.0, the subchannel concept becomes considerably less meaningful, and one is constrained to adopt other flow models.

\section{Diversion Cross-F1ow}

Thermal hydraulic codes are available which calculate subchannel pressures, and hence radial pressure differences. From knowledge of these pressure differences, diversion cross-flow may be calculated if the lateral flow resistance is supplied. This presents a significant 
practical complication since this type of information can apparently only be reliably derived from experimental work which is scarce. St. Pierre ${ }^{(11)}$ has attempted to establish a correlation for cross-flow under single-phase conditions based on data obtained by McNown and Stanford investigators for dividing flow in a manifold, and for two-phase conditions on theoretical grounds.

Recently, experimental data and correlations were obtained by E. Khan, A. Bishop, and F. Engel from which cross-flow and cross-flow resistance within a rod bundle and cross-flow among uncanned rod bundles can be calculated. The correlations show that the resistance coefficient $\mathrm{K}$ for cross-flow between two parallel flow streams is a function of the axial flow velocities, the lateral static pressure difference, the cross-flow and the axial pressure drop. This data which will soon be published can be utilized to evaluate the cross-flow resistance (i.e., the factor Cij of COBRA) and as such will provide the most applicable and interpretable data available in the literature to evaluate this factor. Presently the only data available are from measurements of flow redistribution into branch arm (right angle) pipes used by St. Pierre (as cited above) and from the unpublished English data which is assumed to serve as the basis for the factors in the HAMBO treatment of radial interchannel pressure drop.

Data and Correlations for Forced Mixing

Mixing effects of grids versus wire wrap differ not only in terms of scattered versus directed components but also in terms of the axial 
variation of the degree of mixing. Whereas the mixing intensity due to wire wraps is fairly constant axially, the degree of mixing in grids is a function of the distance downstream and upstream from grid spacers. For example, Bishop ${ }^{(16)}$ fitted his grid data with an exponential type function which showed clearly that mixing downstream from a grid spacer decreased rapidly. At 8-10 inches downstream, the mixing effect was equivalent to the turbulent interchange level. Since flow scattering effects are sensitive to the grid configuration, no generalized correlation has been postulated. Instead, experimentally determined constant factors are genera11y applied to the turbulent interchange contribution to include these grid effects although they are clearly axially varying and significantly dependent on grid spacing.

To date only Moyer has suggested a fundamental approach to predicting flow sweeping effects due to fins or wraps. The model is quite simple and idealized; it expresses the cross-flow rate from subchanne1 $i$ to subchannel $j$ in terms of the following assumption;

(flow pushed from $i$ to $j$ by the (fraction of cross sectional wire per unit length (total axial flow rate in $=\frac{\text { (axial distance over which the }}{\text { (axial }}$ subchanne1 i) helical wire traverses the subchannel cross section)

which, in symbols, is

$$
\frac{w_{i j}}{w_{i}}=\frac{\left(A_{f i} / A_{i}\right)}{(\theta p / 2 \pi)}
$$

This equation does not accurately predict cross-flow in wire wrapped rod bundles, however, because of two basic deficiencies pointed out by Moyer. First, it neglects the effect of coolant slipping over the wire 
instead of being swept along its surface, because of the various properties of real fluids which are not considered. Second, it neglects effects of interference between the actions of different spacers. Moyer attempts to correlate the errors arising from the first of these simplifications by means of a correlating variable $\mathrm{CV}$ based on the following physical reasoning:

1. Slipping should increase with increases in

a. "Axial inertia" of the flow, or tendency of the flow to resist lateral diversion.

b. Obliqueness of the fin across the axis of flow, measured by $d / p$.

c. Peripheral spacing between fins or wires on the rod, $\nabla$.

2. Slipping should decrease with increases in

a. "Viscous forces" in the flow.

b. Height of fins of wires, h.

Hence, the functional form of $\mathrm{CV}$ is postulated as:

$$
\mathrm{CV}=\frac{(\text { "axial inertia") }(\mathrm{d} / \mathrm{p}) \sigma}{\text { ("viscous forces") } \mathrm{h}}=\frac{\mathrm{Re}}{(\mathrm{p} / \mathrm{d})(\mathrm{h} / \mathrm{V})}
$$

Moyer presents data from several experimenters $(14,16,18,27,28,29)$, and he calculates the cross-flow rate predicted by his equation and the correlating variable which applied to each experiment. He plots

$$
R=\frac{\text { predicted mixing }}{\text { measured mixing }}
$$

as a function of $\mathrm{CV}$. It is found that as expected, $\mathrm{R}$ increases with a surprisingly orderly pattern with increasing values of $C V$, and also that the values of $R$ fall on distinct curves which correspond to groups of data 
points which had particular combinations of lattice array, number of pins, number of pins with spacers, and opposing or confluent helices.

Since the publication of Moyer's report, several additional experimental programs have investigated the effects of forced mixing. Table II summarizes the test conditions for those programs which yielded applicable quantitative data.

A program of experimentation in mixing phenomena was carried out in support of the Heavy Water Organic Cooled Reactor (HWOCR). The work described by Pekrul and Cassidy ${ }^{(30)}$ describes cross-flow induced predominantly by flow sweeping on the part of the spiral fin spacers. The test setup includes only two subchannels separated by a throat between two finned pins. The cross-flow is determined (1) by injecting salt into one channel and measuring coolant resistance at various axial heights along the test section, and (2) by cross-correlation of noise signals from two conductivity sensors in different subchannels at different heights.

The work described by Felten ${ }^{(31)}$ uses a 10-pin bundle with spiral fin spacers. The test method is based on the proportionality between electrode resistance and tracer salt concentration. These experiments determine the average value of cross-flow to axial flow rate; and the resulting value agrees, within the limits of error, with the results of Pekrul and Cassidy. 
The most recent phase of the HWOCR work is that reported by Menze1 and Brindley ${ }^{(32)}$. These water tests, on a full 37-pin bundle, used dye injection and spectrophotometer analysis of subchannel effluent. While the two earlier reports, using fewer pins, could only measure (crossflow/axial flow)--denoted $R_{c}$, in $\mathrm{ft}^{-1}$--as a constant value, the fullsize bundle creates enough difference between central subchannel flow rate and bundle average flow rate, so that a slight dependence of $R_{c}$ on bundle average flow rate can be measured. This work also observed significant differences between cross-flow characteristics of central subchannels and peripheral subchannels formed by the outer pins and the flow duct wall. The cross-flow in the peripheral region was about $59 \%$ of that in the central region.

Several investigations in support of sodium cooled reactors have been performed. The thermal-hydraulic program ${ }^{(33)}$ at UKAEA Risley, in support of PFR fuel assembly design used a $5 \frac{1}{2} \mathrm{X}$ scale model of the prototype PFR subassembly in a series of air flow tests using nitrous oxide injection to determine flow distributions and the mixing effect with prototypic grid spacers. It was found that typical grids spaced at 2" intervals increased the turbulent mixing rate by a factor of five over the clean bundle case. In order to relate the observed flow effects in the air tests to the expected thermal effects in sodium, two separate experiments in identical configurations were conducted to determine the value of $6_{M}$ for air and that of $6_{H}$ for sodium. The $6_{M}$ for air was measured by injecting $\mathrm{NO}_{2}$ into the center of air flowing in an $80 \mathrm{~mm}$ diameter 
open pipe and measuring concentration profiles downstream. The $\epsilon_{H}$ for sodium was measured by injecting $600^{\circ} \mathrm{C}$ sodium into the same pipe carrying $200^{\circ} \mathrm{C}$ sodium flow, and measuring temperature profiles downstream. Eichkoff reports that based on preliminary data, $6_{\mathrm{H}}$ (sodium) $/ \epsilon_{\mathrm{M}}$ air $=$ $.6 \pm .1$ over the range of Reynolds numbers of 2 to $6 \times 10^{4}$.

In France, tests have been performed on a $5 \mathrm{X}$ scale model of a 37pin wire wrapped rod bundle, in support of Rhapsodie and Phoenix fuel design; however, neither the experimental results nor the analytical techniques used to interpret these data have been published.

Bump ${ }^{(34)}$ reports the results of coolant mixing tests in the wire wrapped 91-pin EBR-II bundle. Based on these results, mixing causes the peripheral subchannel temperature rise to increase by $17 \%$ and the adjacent interior subchannel rise to decrease by $22 \%$. Thus, mixing causes a significant homogenization of outer subchannel temperature rises from the conditions without mixing of the peripheral subchannel temperature rise equaling $60 \%$ of that of the adjacent interior subchannel.

Bump reports mixing values in the form

$$
\frac{w^{\prime}{ }_{i j}}{w_{i}} \frac{{ }_{e_{i}}{ }^{z}{ }_{i j}}{c}=\text { measured value, i.e., 非 }
$$

This is equivalent to

$$
M_{i j}=\frac{w_{i j}^{\prime}}{G_{i} c}=\mid \frac{d_{e}}{z}
$$


which does not express the Reynolds number dependence of Equation (5). The additional flow sweeping data previously analyzed by Moyer is presented along with the EBR-II data in a form following the suggestion of Shimazaki ${ }^{(27)}$ that the product of $\frac{w^{\prime}{ }_{i j}}{W_{i}} \times p$ should be a constant. This form does not correlate the data and was improved upon by Moyer as previously described.

Quantitative measurements of flow distributions were made ${ }^{(35)}$ in a $3 \mathrm{x}$ scale prototype of the SEFOR fuel bundle, which consisted of six oneinch diameter rods packed around a special tightener rod. This fuel design was dictated by the function of the SEFOR reactor, and is not characteristic of fast breeder bundle designs. Consequently, the resulting mixing data is not directly applicable to such designs which utilize smaller rods and either grid or wire wrapped spacers.

\section{AVAILABLE CODES FOR SUBCHANNEL ANALYSIS}

The available subchannel analysis codes can be catagorized with respect to which mixing effects they consider. The codes which focus on a single effect are first summarized. Then the more comprehensive codes which handle several effects are presented. This discussion summarizes the fundamental assumptions and correlations adopted in each code. Table III summarizes the features of each of these existing codes. 
Codes Which Consider Turbulent Interchange Only

HECTIC-II ${ }^{(36)}$ developed for the Army Gas Cooled Reactor system Program is limited to single-phase flow analysis. It was one of the earliest thermal hydraulic codes to consider the effects of turbulent interchange. The turbulent mixing analysis is based on the assumed equivalence of the eddy diffusivities of momentum and heat, $6_{\mathrm{M}}$ and $6_{\mathrm{H}}$. The eddy diffusivity in each subchannel is computed as if it were equivalent to that in the center of a circular tube with the same Reynolds numbers (based on the hydraulic diameter) as calculated for the particular flow passage. The diffusivity at the center of a circular tube is assumed to be equal to the maximum diffusivity, as calculated from the Nikuradse universal velocity profile equation. The code includes an adjusting factor, loaded as program input, which allows the effect of turbulent mixing to be increased, decreased, or eliminated as desired. The Manta mode1 ${ }^{(37)}$ developed for the nuclear superheat program is also limited to single-phase flow analysis and accounts for turbulent interchange in the same way as does HECTIC-II. It is the only available code, however, which includes effects of molecular conduction within the coolant and for this reason is useful in analysis of liquid metal systems. The model of Lowe ${ }^{(38)}$ calculates the effect of turbulent interchange on core thermal performance, and is formulated in terms of the effect on the hot channel factor for enthalpy rise, $\mathrm{F}_{\Delta^{\mathrm{H}}}$. The discrete rod and associated subchannel geometry characteristic of parallel flow rod bundles 
is idealized by a narrow channel of width (a), through which the heat is added to the coolant, and thickness (s), across which coolant mass diffuses. Equality of momentum and thermal eddy diffusivity is assumed. Lowe develops results for $F_{\Delta H}$ versus nondimensional channel width parametrically for varying eddy diffusivities and channel geometries. The results illustrate that length increases or channel width decreases cause mixing increases due respectively to longer diffusion p riod for a given axial velocity and to shorter radial distance between effective subchannel centerlines.

Lowe's results can be applied to cases with different axial power shapes through a defined overall nondimensional diffusion coefficient because the hot channel factor relates the enthalpy rise to the average enthalpy rise. However, the results have been computed with a specific radial power distribution which must be compared to the power distribution of interest.

Codes Which Consider Diversion Cross-Flow Only

Winfrith's Bowline code ${ }^{(3)}$ and a code ${ }^{(39)}$ developed by Schramm and Berland for analysis of the SNAP 4 core consider diversion cross-filow. In the Bowline code, each subchannel was considered separately and the flow rate at each axial station was computed to give the same pressure gradient as that calculated from the mixed flow model.

The model of Schramm and Berland also does not allow continuous cross-flow across the subchannel boundaries. It utilizes a "discontinuous 
nodal flow model approximation," or DNF model, which considers crossflow to occur only along a very small axial distance at the entrance of each axial segment. The balance of the segment is treated as a onedimensional compressible flow problem. The DNF model is restricted to situations in which axial flow resistance is a monotonic function of radial position across the core, which means that cross-flow may occur in only one direction--center to edge, or vice-versa. Hence, this model may not be applicable to rod bundle geometries, in which crossflow may be either direction depending on radial location. Codes Which Consider Flow Sweeping Only

The G-20 code by 01daker ${ }^{(40)}$ computes subchannel conditions considering the coolant mixing promoted by wire wrap. This method assumes the flow direction and relative intensity of coolant streams within the bundle and assigns normalized flow factors to each stream which yields a net mass balance across the bundle. The actual mass flow rates within the bundle result from the product of the flow factor and an input mixing flow rate. This mixing flow rate is assumed proportional to the average linear velocity of the coolant.

The validity of the assumed mixing flow rate and flow factors can be determined by comparison of predicted and experimental clad temperatures. Oldaker reports close agreement for organic coolants in two experiments $(X-721$ and $U-301)$. Sander's modified U-3 code ${ }^{(41)}$ developed for the HWOCR program is identical in principle to the G-20 code but 
defines flow factors for the HWOCR bundle cross section which contained opposing spiral fins and rods of two diameters.

\section{Codes Which Cover Several Mixing Effects}

There are presently available a number of calculational techniques of relative sophistication which consider several of the individual mixing effects discussed above. In addition, since these codes were developed for water reactor application, they handle two-phase flow conditions with varying assumptions on the number of boiling regions and associated void fraction and pressure drop correlation. These codes are THINC ${ }^{(42)}$,

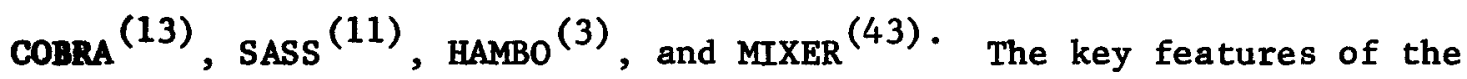
MIXER code are covered in Table III without further discussion because a description of this $c$ de has not been published.

The THINC code was developed for analysis of hot channel factors in pressurized water reactors considering the effects of diversion crossflow and turbulent interchange. Reference 42 presents the experimentally determined turbulent interchange flow rate and the diversion (1atera1) cross-flow resistance from dividing manifold data utilized in THINC. Using the THINC code, it was found that in cases where the lateral resistance was sma11 (less than 0.1 of the axial flow resistance) the neglect of lateral pressure drops, and, hence, diversion cross-flow effects, resulted in less than one percent error in the axial flow rates. Based on these results, THINC was modified to THINC-II, in which convergence 
is obtained by requiring uniform static pressure at each axial elevation, thus neglecting the effects of diversion cross-flow induced by lateral pressure gradients. Additional analytic and experimental effort have been applied to the THINC codes since their formulation, although the models employed within the codes have not been published. In particular, it is expected that significant understanding of the role of diversion cross-flow and axial grid spacers on mixing within the PWR bundle has been developed since publication of Reference 42 .

The COBRA code is among the most recent of the subchannel analysis codes which has considerable flexibility and capability in the detail in which arbitrary geometric and test conditions can be handled. It considers both turbulent interchange and diversion cross-flow but in each case requires an input value to characterize their magnitude. As discussed in the last section on current experimental programs, specific tests are being performed to determine the values of these constants. A parametric study indicated that while assignment of a value for the diversion cross-flow resistance was important to insure calculational stability for some geometries, the numeric value was not of significant consequence to local subchannel parameters unless very closely spaced rods were considered.

The SASS program has been developed concurrently with COBRA and is the analoguous Canadian code. Both turbulent interchange and diversion cross-flow are considered and in each case different expressions are proposed for these effects under single-phase and two-phase conditions. 
For turbulent interchange, available single-phase eddy diffusivity data was plotted and the following correlations adopted:

For $\operatorname{Re}<5 \times 10^{3}$

$$
\begin{gathered}
\frac{\epsilon_{M}}{u_{i} d_{e_{i}}}=2.3 \times 10^{6} \mathrm{Re}^{-2.39} \\
\text { For } 5 \times 10^{3}<\operatorname{Re}<2 \times 10^{5} \\
\frac{\epsilon_{M}}{u_{i} d_{e_{i}}}=0.0205 \mathrm{Re}^{-0.217}
\end{gathered}
$$

For the two-phase case, based on several referenced theoretical analyses, the turbulent interchange flow rate was assumed to increase over that obtained in the single-phase case by the ratio of the two-phase to singlephase friction factors. The friction factors are expressed by St. Pierre in terms of the Martinelli-Nelson two-phase friction factor multiplier and the Jones empirical pressure mass flow adjustment parameter.

For the diversion cross-flow, correlations for cross-flows resulting from radial pressure gradients under single-phase conditions were obtained by plotting and fitting data from McNown and Stanford for dividing flow in a manifold. For the two-phase case since no experimental data or theoretical analysis were found in the literature, St. Pierre derived an expression for cross-flow in a continuous blowing manifold (horizontal pipe with continuous slit of width b) for the two-phase case by analogy with the single-phase solution. The SASS code incorporates 
the above correlations and, thus, predicts local subchannel conditions without need for arbitrary input constants for mixing flow rates.

The HAMBO code appears to be the most comprehensive of the published subchannel analysis codes. Not only does it propose adjusting factors to account for forced mixing effects, but it also incorporates adjustments relative to turbulent interchange and diversion cross-flow to account for deviations from the normally adopted idealizations. The presence of these correction factors suggests that HAMBO has been extensively tested by experiment although no reference is provided to such experimental data.

The turbulent interchange flow rate is calculated as in HECTIC for single-phase, and has been extended to the two-phase region using the homogeneous theory. It is adjusted, however, by the following factors: 1. Inversely proportional to a shape factor, $\mathrm{Sm}$, for the gap geometry which is a dimensionless function of $\mathrm{c} / \mathrm{z}_{i j}$ and the subchannel geometry. The base case $(\mathrm{Sm}=1)$ is a rectangular diffusion passage of width $c$ and length $z_{i j}$. A table is given which presents "typical values for mixing" between (a) two rods of equal diameter, and (b) one rod and a plane approximating the geometry between two outer subchannels in a large rod cluster. It shows decreased mixing for the two rod versus rod and plane case and decreased mixing with decreasing $c / z_{i j}$ ratio. This table illustrates the significance of the rod to rod gap on the effective mixing distance between subchannels. 
2. A term describing the modifying effect of diversion cross-flow on turbulent interchange. All other codes consider these processes as independent. In HAMBO turbulent interchange is assumed completely suppressed if it is only $25 \%$ or less than the diversion cross-flow rate and proportionally reduced if it is greater than $25 \%$ according to the expression

$$
w^{\prime}{ }_{i k} \underset{\text { cross-flow) }}{\text { (corrected for }}=w_{i k}^{\prime}\left[1-\left(\frac{w_{i k}}{2 w_{i k}^{\prime}}\right)+\left(\frac{w_{i k}}{4 w_{i k}^{\prime}}\right)^{2}\right]
$$

3. A multiplicative constant, $F_{m}$, to allow for turbulence promotion within the cluster due to wire wraps and grids and to allow for analysis of experimental data. For rod gaps of about .100 inch, the following values of $F_{m}$ were given:

$$
\begin{array}{ll}
\text { Clean Systems } & F_{\mathrm{m}}=2-5 \\
\text { Gridded Systems } & \mathrm{F}_{\mathrm{m}}=5-10 \\
\text { Wrapped Systems } & \mathrm{F}_{\mathrm{m}}=10-20
\end{array}
$$

It was further stated that $F_{m}$ appears inversely proportional to changes in rod spacing about the .100 inch value. This would seem reasonable for forced mixing effects where "slipping" would be reduced for smaller gaps. For clean systems, however, increased gap width would seem to promote turbulent interchange rather than suppress it.

The diversion cross-flow resistance is stated as passing radially between the rod gap between subchannels and as based on use of the homogeneous theory multiplier in the two-phase region. Although the acceleration 
component of the pressure drop was not taken into account, Bowring states that predicted subchannel conditions were not sensitive to the value of the lateral resistance. Further details of the treatment of diversion cross-flow in HAMBO must await publication of Part 2 of the reference which will contain the complete derivation of the mixing equation.

\section{DEVELOPMENT OF TECHNIQUES FOR LIQUID METAL APPLICATION}

In assessing the applicability of these available data and analytic techniques to the resolution of design problems in liquid metal cooled fuel bundles, the following characteristics of LMFBR fuel systems are significant:

\section{High Thermal Conductivity of Sodium}

This parameter has two effects based on our definitions of mixing phenomena. First, it introduces a molecular conduction mechanism in addition to the convective mixing effects upon which our attention has been focused. This conduction effect can be comparable to significant turbulent interchange as evidenced by results of Padilla ${ }^{(7)}$ who found that inclusion of the conduction is equivalent to a $\beta$ value of about .005 (for $\epsilon_{H} / \epsilon_{M}=1$ ). Second, the ratio of the eddy diffusivity of heat to that of momentum for sodium is generally not unity but dependent on Reynolds number. In addition to the recent data of Eickhoff, et al., in his review article Dwyer ${ }^{(44)}$ summarizes the methods available for predicting the effective average value of 
$\epsilon_{\mathrm{H}} / \epsilon_{\mathrm{M}}$ denoted as $\bar{\psi} \cdot \bar{\psi}$ approaches zero at low Reynold's numbers since the hotter eddy particles lose heat to the surrounding liquid metal. At high Reynolds numbers, $\bar{\psi}$ approaches unity since the eddies apparently move so fast that they lose an insig ificant amount of heat in transit. Significant interest does exist in the cases of distorted or blocked pin bundles in which case low Reynolds numbers do apply.

2. Subchanne1 Geometry

As illustrated on Table I, LMFBR fuel geometries are characterized by sma11 diameter $\left(\mathrm{d} \leq .3^{\prime \prime}\right)$, tightly packed $(\mathrm{p} / \mathrm{d} \leq 1.3)$ fuel pin arrays. These geometries introduce subchannel temperature imbalances which tend to produce some pin bowing which may not be totally limited by the pin restraint scheme. Additional alteration of the channel flow area will be introduced by swelling of the oxide fuel pins. Up to $2-3 \%$ diametra1 pin growth without clad failure is possible. For a $.250 "$ pin with a $.040 "$ rod to rod spacing, a $15 \%$ reduction in rod to rod spacing is possible.

Both these effects could cause alteration of certain subchannel geometries and induce significant diversion cross-flow.

\section{Pin Support Method}

For those systems with tight pin to pin spacings, wire wraps have been selected while grids have been chosen for systems with larger spacings. For those systems utilizing grid spacers, the subchannel thermal imbalances characteristic of all LMFBR designs offer incentive to attempt to incorporate mixing vanes in the grid. 
The applicability to LMFBR designs of the cited data taken for water reactor application is severely limited by the differences in geometry and support hardware which are summarized in Table IV. Specifically, the recently tested heavy water arrays, while tightly packed $(\mathrm{p} / \mathrm{d} \cong 1.1)$ like LMFBR arrays, employ wart-type spacers. On the other hand, the light water arrays, while utilizing grid spacers of the types under consideration for LMFBR application, have significantly looser packed arrays $(\mathrm{p} / \mathrm{d} \cong 1.3)$. Further, in both cases large diameter rods are used $\left(d \geq .4^{\prime \prime}\right)$ versus the small diameter pins of the LMFBR $\left(d \leq .3^{\prime \prime}\right)$. In view of the lack of knowledge of the effects of these geometric variables on mixing, much of this data is of limited direct value to gridded IMFBR application. Relative to wire wrapped LMFBR application, the early work on tightly packed heavy water arrays which employed wire wrap and were run under single-phase conditions is of interest. However, even these data are not directly applicable because of the large rod diameters and the arrays (Figure 1a) employed. Note that the arrays for this case are departures from a normal triangular configuration and are obtained by rotating the outer ring of a normal triangular array by $15^{\circ}$ yielding five rather than two characteristic subchannels.

The available analytic techniques do form a foundation upon which a method applicable to LMFBR design can be based. These techniques, particularly the more comprehensive codes are undergoing continual 
refinement. The improvements being incorporated into these codes which are used in water reactor application center in the following areas:

\section{Two-Phase Flow Description}

Numerous improvements in definition of flow regimes and their associated void fraction and pressure drop characteristics. This definition is necessary to develop expressions for the various mixing effects under two-phase conditions along the lines attempted by St. Pierre.

In this regard, there appears to be a difference of opinion in the literature regarding the importance of diversion cross-flow for undistorted geometries under two-phase conditions. Some have attached great importance to determining diversion cross-flow resistance while others have negated its importance.

\section{The Lumped Parameter Approach}

The geometric assumption of effective mixing distance and rod to rod separation between subchannels; the assumptions of characterizing mixing flow rates between subassemblies in terms of mean subchannel Reynolds numbers and enthalpies.

3. Increased Flexibility in Subchannel Geometric Description Capability to consider effects of rod bowing or subchannel blockage by foreign objects over channel length.

\section{Forced Mixing Effects}

Both grid (flow scattering) and wire wrap (flow sweeping) effects. 
In this regard the use of mixing vanes to promote flow sweeping at minimum pressure drop is of interest. In any event, accurate prediction of mixing effects will require increasingly accurate pressure drop correlations.

\section{Interaction of Various Mixing Effects}

Establishment of the degree of interaction between turbulent interchange, diversion cross-flow, flow scattering and flow sweeping. With the exception of the efforts in the two-phase flow description, these improvements are directly applicable to LMFBR needs. Noting the major LMFBR characteristics of conduction effects, subchannel area changes and forced mixing effects, it appears that efforts should be primarily directed to these areas. In view of Bowring's statements which indicated that grids and wire wrap can cause respectively a two to three to six-fold enhancement of mixing over a bare system, it seems particularly appropriate to emphasize efforts in this area. The data of Bump on the EBR-II wire wrapped bundle is a significant positive contribution to this area. On the other hand, the presently available correlations for turbulent interchange (with a suitable ratio of $6_{\mathrm{H}} / 6_{\mathrm{M}}$ incorporated) may already be sufficiently accurate for LMFBR application compared to the importance of this effect versus conduction and forced mixing effects.

\section{CURRENT MIXING STUDIES IN PROGRESS}

The foregoing discussion summarized the analytic and experimental mixing 
information available in the open literature and its applicability to LMFBR designs. Undoubted1y, considerable additional information has been developed in support of current commercial reactor efforts which is retained as proprietary.

There is also currently substantial additional effort underway summarized in Table V. Under the USAEC/AECL Cooperative Program on Heavy Water Moderated Power Reactors, Columbia University and Battelle Northwest Laboratory (BNWL) are involved in significant efforts on coolant mixing. The experiment efforts at both locations are designed to provide data for testing and modification of the COBRA code.

The Columbia effort involves measurements of individual subchannel conditions within the ful1 prototypic BLW bundle geometry (ASME 66-WA/ HT46), whereas the BNWL effort involves measurements in simulated adjacent subchannels and is, thus, aimed at investigation of the specific variables of wart spacers and rod spacing. The bundle geometry under test at Columbia is shown in Figure la which identifies the subchannels. which are sampled. The experiment is unique in that the selected subchannel conditions of enthalpy and flow rate are determined by isolating the subchannel at the exit end of the heated length and withdrawing the sample at a controlled rate. It is critical to assure that the sample withdrawn represents coolant conditions in an undisturbed bundle. Two precautions are employed--first, the rate of withdrawal is established by adjusting the subchannel flow until a null reading is obtained between 
a pressure tap at the inlet of the isolated channel and a pressure tap at an equivalent point at another radial location in the assembly; second, the data is obtained by a series of experiments in which the number of isolated subchannels which are simultaneously sampled is increased from one to three (albeit in identical geometry, but physically different bundles). The nulling method aims at eliminating perturbations between an undisturbed and sampled bundle and the comparative series of measurements aims at eliminating or at least identifying perturbations due to simultaneously sampling multiple subchannels. Referring to Figure la, runs will be accomplished by individually sampling subchannels No. 1 and 5 (the most thermally limiting subchanne1) and by simultaneously sampling subchannels No. 1, 2, and 3 . The results from this experiment should be of considerable value in assessing the effect of local channel conditions on the critical heat flux since they wil1 be run over a series of input powers approaching to within $65-75 \%$ of the critical heat flux limit. The Columbia program contemplates similar testing of a square pitch, more open bundle consisting of an array of about 20 rods, .422" rod outside diameter, .133" rod to rod spacing and .200" rod to wall spacing. Additional measurements on 28 and 37 rod bundles will also be performed.

The BNWL experimental effort involves direct measurement of mixing effects due to wart-type spacers typical of the Columbia BLW bundle. The test section simulates two adjacent channels in a square array with rod 
separation maintained by wart-type spacers. Mixing between the channels will be measured utilizing heavy water and lithium ion tracers. As with the Columbia investigations, heat fluxes about two-thirds of the expected critical heat fluxes will also be employed.

The BNWL analytic effort includes improvement of the COBRA code capabilities and testing of the code's ability to predict local subchannel conditions and reported rod bundle boiling burnout data. The improvements under consideration include accounting of

1. Variable rod gap and channel area long the bundle length and different hydraulic characteristics in individual channels.

2. Effects of subcooled void fraction.

3. A two-phase mixing and transverse flow resistance correlation.

4. Forced mixing effects due to various rod spacers (warts, wire wraps, grids).

5. Molecular conductivity in the coolant.

The code's ability to predict local rod bundle subchannel conditions will be tested specifically with the Columbia and BNL data as well as available critical heat flux data. In this regard, BNL has underway under the USAEC/AECL program a concurrent experiment measuring the effects of rod spacing over the range of .015 to $.080^{\prime \prime}$ on the critical heat flux.

A comparable Canadian experimental and analytic effort is underway under the sponsorship of AECL's Chalk River Nuclear Laboratory. The work is centered on experimenting with a variety of coolants (air, water, air 
water mixtures, and freon) and applying these data to test the models of Rogers and St. Pierre within the framework of the COBRA and SASS codes.

Present experimental effort utilizes rectangular elements and tubes with dividing slits of various lengths and widths to simulate gaps between adjacent subchannels. This exploratory work is being done with air and water individually (single-phase) and air-water mixtures (twophases). The emphasis is on study of turbulent interchange and diversion cross-flow, characterizing in particular the resistance to crossflow. Subsequent studies will use more exact subchannel geometry and be extended to single and two-phase freon coolant. Experimental work of this type will also be done in a loop being constructed at the University of Windsor. Initial work will be with single-phase (air, water) with plans to convert the loop to two-phase capability.

Analytic efforts will apply these data to evaluation of the two models noted above. The SASS model refinement will be primarily based. on University of Windsor mixing data. In addition to this effort on code development of the detailed mixing phenomenon, a design survey method is being developed to assess different arrangements of fuel bundles in terms of subchannel enthalpy imbalance assuming no mixing. This assessment is expressed as a bundle imbalance number and agrees with critical heat flux experiments on a variety of 18 rod bundles in 
which the flow disturbances (end plates and spacers) are identical. Apparently any change in flow disturbances seriously affects mixing and requires an adjustment of the bundle imbalance number scale. This is sometimes available from the catalogue of test results on similar configurations.

This technique of bundle assessment is incorporated into a calculation procedure which tests all feasible designs of a bundle with a specified number of rods. In this way, one can determine the design requiring the least amount of mixing and for a given amount of mixing that design which should have the maximum thermal efficiency.

The remaining significant program directed at water reactor application is being carried out by the General Electric Company under Project Agreement No. 44 with the USAEC. In this program, extensive measurements of the flow structure in tubular, eccentric annulus, and bare and grid supported, square arrays of nine heated rods will be made. These include (1) flow regime, (2) subchannel velocity distribution and velocity gra- . dients for each phase, (3) density distribution and density gradients, (4) local wall shear, and (5) for annular dispersed flow the liquid film thickness, liquid film flow rate and time varying character of the interface between liquid film and core. Obviously, significant analysis of mixing effects will be possible utilizing this data on subchannel microstructure. 
A11 of the above efforts are directed at u1timate water reactor application, and therefore are emphasizing understanding of two-phase mixing characteristics. Because of the different LMFBR considerations of array geometry and single-phase operating condition, experimental efforts specific to LMFBR application are being carried out in support of the Fast Flux Test Facility (FFTF) project. Initially, following instrumentation checkout, isothermal adjacent subchannels experiments in water utilizing full scale and $4 \mathrm{X}$ geometry will be performed:

Following this work, a full scale undistorted 217 pin, wire wrapped bunde and 37 pin wire wrapped bundle with varying pin distortions will be flow tested in water. Mixing effects will be measured utilizing noise analysis techniques confirmed by the earlier tests. However, such data wil1 not permit direct experimental confirmation of predicted FFTF bundle behavior due to lack of prototypic radial power distribution and absence of sodium conduction effects. Additional experiments in sodium with several heated rods in an assembly of dummy rods could supplement the available data. However, in view of the present expense and difficulty in running heated multi-pin experiments in sodium with LMFBR geometries, such work is not planned. As additional single-phase water becomes available and interpreted through improved codes, the significance of the unconfirmed assumptions can be assessed. In addition, it may be possible from the twin channel data to deduce the scaling laws applicable to mixing 
phenomenon and thus to design a heated multi-rod experiment in sodium utilizing larger ( $2 \mathrm{X}$ ) heated pins to assess these assumptions. Such pins of . $5^{\prime \prime}$ diameter capable of operation at adequate heat fluxes are already available.

Mixing test utilizing single heated pins in sodium are being conducted by the Westinghouse Advanced Reactor Division to determine the effect of mixing produced by grids and spacers on local coolant and clad temperatures. In these tests, a heater rod is inserted into an annulus and the gap is maintained concentric by use of spacer grids. The heater clad temperature is measured upstream, at the grid, and downstream from the grid. Identical tests are run for comparison without grids.

General Electric, under the Fast Ceramic Reactor Program (Project Agreement No. 10) with the USAEC, is conducting related measurements in triangular bare pin arrays under isothermal conditions. Central and peripheral subchannels within seven rod bundles will be probed for local velocity profiles. As stated relative to the measurements of Eifler and Nijsing, while these isothermal velocity profile measurements are not directly applicable to mixing phenomena, they will be of value if and when the lumped parameter subchannel approximation is refined by taking account of detailed local flow structure. 
- 
TABLE I

Subassembly Geometries Typical of LMFBR and U.S. Fast Reactor Designs

(Al1 data from ANS-101, National Topical Meeting - Fast Reactors, April, 1967, or supporting references unless otherwise indicated)

\begin{tabular}{|c|c|c|c|c|c|c|c|c|c|c|c|}
\hline & $\begin{array}{c}\text { Reactor } \\
\text { Power } \\
\text { (MW) } \\
\end{array}$ & Fuel Type & $\begin{array}{c}\text { Average } \\
\text { Outlet } \\
\text { Temperature } \\
\left(F^{\circ}\right) \\
\end{array}$ & $\begin{array}{c}\text { Nominal } \\
\text { Axial } \\
\text { Velocity } \\
(\mathrm{ft} / \mathrm{sec}) \\
\end{array}$ & $\begin{array}{c}\text { Clad Hot } \\
\text { Spot } \\
\text { Limit } \\
\text { (Fo) } \\
\end{array}$ & $\begin{array}{l}\text { Pins per } \\
\text { Assembly }\end{array}$ & $\begin{array}{c}\text { Rod } \\
\text { Diameter } \\
\text { (inches) }\end{array}$ & $\begin{array}{c}\begin{array}{c}\text { Rod to } \\
\text { Rod } \\
\text { Spacing } \\
\text { (inches) }\end{array} \\
\end{array}$ & $\begin{array}{c}\text { Pitch/ } \\
\text { Diameter } \\
\text { Ratio } \\
\end{array}$ & $\begin{array}{c}\text { Rod } \\
\text { Support } \\
\text { Method } \\
\end{array}$ & $\begin{array}{l}\text { Support } \\
\text { Hardware } \\
\text { Axial } \\
\text { Pitch } \\
\text { (inches) } \\
\end{array}$ \\
\hline Rhapsodie - Core I (France) & 20 & Mixed Oxide & 932 & 21 & $1110-1200$ & 37 & .264 & .031 & 1.12 & $\begin{array}{l}\text { Extruded } \\
\text { Fin }\end{array}$ & 5 \\
\hline Phoentx (France) & 600 & Mixed Oxide & $-*$ & - & 1292 & 271 & .234 & - & - & Wire Wrap & - \\
\hline Prototype Fast Reactor (England) & 600 & Mixed Oxide & $1040-1085$ & 20 & 1292 & 321 & .230 & .060 & 1.13 & Grtd & 4 \\
\hline BOR (Russian) $(5)$ & 60 & Not Yet Chosen & 1112 & 32.5 & $1472 * *$ & 37 & .240 & .024 & 1.10 & Wire Wrap & - \\
\hline BN-350 (Russian) (5)(6) & 1000 & Mixed Oxide & 986 & 26 & - & 163 & .240 & .036 & 1.15 & Grid & - \\
\hline Fast Flux Test Facility ${ }^{(7)}$ & 400 & Mixed Oxide & $800-900$ & 26 & 1060 & 217 & $\begin{array}{c}.230 \text { to } \\
.240\end{array}$ & .040 & 1.17 & $\begin{array}{l}\text { Wire Wrap } \\
\text { or Grid }\end{array}$ & 12 \\
\hline GE Demonstration Reactor & 750 & Mixed Oxide & 1100 & 14.4 & $1250-1275$ & 169 & .230 & .072 & 1.31 & Grid & - \\
\hline W Prototype Reactor & 540 & $\begin{array}{l}\text { Carbide (Na } \\
\text { Bonded) }\end{array}$ & 1000 & - & 1292 & 168 & .286 & .094 & 1.33 & Grid & 8 \\
\hline Experimental Breeder Reactor - Core II & 52.5 & $\begin{array}{l}\text { U-5 w/o } \\
\text { Fissium (Na } \\
\text { Bonded) }\end{array}$ & 890 & 26 & 1060 & 91 & .174 & .049 & 1.28 & Wire Wrap & 6 \\
\hline Enrico Fermi Plant & 200 & $\mathrm{U}-10$ w/O MO & 800 & 16 & - & 140 & .158 & .041 & 1.26 & Grid & $\begin{array}{l}1-7 / 8 \\
\text { (Restrict } \\
\text { Movement) } \\
7 \frac{1}{2} \text { (Grip } \\
\text { pins) }\end{array}$ \\
\hline
\end{tabular}

* Indicates parameter not speciffed in available references.

**'Maximum can temperature with allowance for possible overheating." 
TABLE II

Summary of Some Experimental Programs Since Moyer's Report

\begin{tabular}{|c|c|c|c|c|c|c|c|c|c|c|c|c|c|c|c|c|c|}
\hline \multirow{3}{*}{$\begin{array}{c}\text { Source } \\
\text { Tarasuk } \\
\& \\
\text { Kempe }\end{array}$} & \multirow{3}{*}{$\begin{array}{l}\text { Ref. } \\
\text { No. } \\
12\end{array}$} & \multicolumn{6}{|c|}{ Test Geometry } & \multicolumn{3}{|c|}{ Spacers } & \multicolumn{6}{|c|}{ Flon conditions } & \multirow{3}{*}{\begin{tabular}{l}
\multicolumn{1}{c}{$\begin{array}{c}\text { Exper 1mental } \\
\text { Techn (que }\end{array}$} \\
(Quantity Measured) \\
LiNo Tracer Con- \\
centfation
\end{tabular}} \\
\hline & & \multirow{2}{*}{$\begin{array}{c}\text { Number of Rods } \\
19\end{array}$} & \multirow{2}{*}{$\begin{array}{l}\text { Mixing } \\
\text { Array } \\
\mathrm{T} \leftrightarrow \mathrm{s}\end{array}$} & \multirow{2}{*}{$\begin{array}{c}\begin{array}{c}\text { Diam. } \\
\text { in. }\end{array} \\
1.87\end{array}$} & \multirow{2}{*}{$\begin{array}{l}\text { Pitch } \\
\text { in. } \\
2.03\end{array}$} & \multirow{2}{*}{$\begin{array}{l}\frac{\text { P1tch }}{D 1 \text { sm. }} \\
1.083\end{array}$} & \multirow{2}{*}{$\begin{array}{l}\text { L } \\
\text { in. } \\
61\end{array}$} & \multirow{2}{*}{$\begin{array}{c}\text { Type } \\
\text { None }\end{array}$} & \multirow{2}{*}{$\begin{array}{c}\text { Effective } \\
\text { Directional } \\
\text { Conflguration } \\
\\
--\end{array}$} & \multirow{2}{*}{$\begin{array}{l}\text { Pitch } \\
\text { In. } \\
--\end{array}$} & \multirow{2}{*}{$\begin{array}{l}\text { Fluid } \\
\text { Water }\end{array}$} & \multirow{2}{*}{$\frac{\underset{F}{\text { Temp. }}}{150}$} & \multirow{2}{*}{$\begin{array}{l}\text { Avg. } \\
\text { psia } \\
15(?)\end{array}$} & \multirow{2}{*}{$\begin{array}{r}1 \mathrm{~b} / \\
\mathrm{hr}-\mathrm{ft}^{2} \\
\times \quad 10^{-6} \\
\end{array}$} & \multirow{2}{*}{ 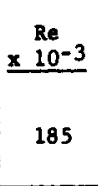 } & \multirow{2}{*}{$\begin{array}{c}\begin{array}{c}\text { Radisl Heat } \\
\text { D1stributionkt }\end{array} \\
\text { Unheated }\end{array}$} & \\
\hline & & & & & & & & & & & & & & & & & \\
\hline Clarke & 23 & 19 & $\mathrm{~T} \leftrightarrow \mathrm{S}$ & 0.60 & 0.65 & 1.083 & 19.5 & $\begin{array}{c}\text { Local } \\
\text { Profections }\end{array}$ & None & -- & Water & $\begin{array}{c}80-100 \\
\text { cold } \\
180-200 \\
\text { hot }\end{array}$ & $15(?)$ & $\begin{array}{l}1.43 \\
\text { to } \\
3.71\end{array}$ & $\begin{array}{r}35 \\
\text { to } \\
127\end{array}$ & Unheated & Hot Water Injection \\
\hline $\begin{array}{l}\text { Rowe } \\
\& \\
\text { Angle }\end{array}$ & 19 & $\begin{array}{l}\text { Simulated } \\
\text { Adfacent } \\
\text { Subchannels }\end{array}$ & $\mathrm{T} \leftrightarrow \mathrm{s}$ & $\begin{array}{l}.563 \\
.563\end{array}$ & $\begin{array}{l}.647 \\
.583\end{array}$ & $\begin{array}{l}1.149 \\
1.036\end{array}$ & 60 & None & -- & -- & Water & $\begin{array}{l}330 \\
\text { and } \\
510\end{array}$ & 900 & $\begin{array}{c}1 \\
2 \text { and } \\
3\end{array}$ & $\begin{array}{r}26 \\
\text { to } \\
130\end{array}$ & Uniform & Subchannel Delta T \\
\hline $\begin{array}{l}\text { Biggs } \\
\& \\
\text { Rust }\end{array}$ & 21 & 36 & $\mathrm{~s} \leftrightarrow \mathrm{s}$ & 0.5 & 0.7 & 1.40 & 60 & None & -- & $\cdots$ & Water & $80(?)$ & $15(?)$ & $\begin{array}{l}.224 \\
\text { to } \\
1.35\end{array}$ & -- & Unheated & $\begin{array}{l}164 \mathrm{DyNO}_{3} \text { Tracer } \\
\text { Concentration by } \\
\text { Activation Analya1s }\end{array}$ \\
\hline Dean & 22 & 182 & $s \leftrightarrow s$ & .435 & .533 & 1.23 & 120 & Grids & None & $\begin{array}{l}10.5 \\
\text { and } \\
15.75 \\
\end{array}$ & Water & -- & -- & $-\cdot$ & $\begin{array}{r}15.5 \\
\text { to } \\
22.9 \\
\end{array}$ & $\begin{array}{l}4 \text { corner and } \\
4 \text { edge rods } \\
\text { only }\end{array}$ & Subchannel De1ta $\mathrm{T}$ \\
\hline $\begin{array}{c}\text { Eifler } \\
\text { \& } \\
\text { N1jsing }\end{array}$ & 24 & 4 & $\mathrm{~T} \leftrightarrow \mathrm{T}$ & 1.58 & $\begin{array}{l}1.66 \\
1.74 \\
\text { and } \\
1.82 \\
\end{array}$ & $\begin{array}{c}1.056 \\
1.100 \\
\text { and } \\
1.157\end{array}$ & 47 & None & -- & -- & Water & 176 & 52 & 0.11 & $\begin{array}{l}26 \\
28 \\
30 \\
\end{array}$ & Unheated & $\begin{array}{l}\text { Intra-Subchannel } \\
\text { Velocity Profiles - } \\
\text { (No Direct Mring } \\
\text { Deta - See Text) } \\
\end{array}$ \\
\hline Eindhoven $*$ & 25 & $\begin{array}{c}\text { S1mulated } \\
\text { Adjacent } \\
\text { Subchannels }\end{array}$ & $s \leftrightarrow s$ & .67 & .79 & 1.175 & 39 & None & -- & $\cdots$ & Water & $\begin{array}{c}300 \\
\text { to } \\
640\end{array}$ & $\begin{array}{l}150 \\
\text { to } \\
2100\end{array}$ & $\begin{array}{l}.73 \\
\text { to } \\
2.2 \\
\end{array}$ & & $\begin{array}{l}\text { 4:3 Ratio Be- } \\
\text { tween channels }\end{array}$ & $\cdots$ \\
\hline & & a) 6 in a row & $\begin{array}{l}\text { Between } \\
\text { Hem1- } \\
\text { spheres } \\
\text { across } \\
\text { gaps }\end{array}$ & $\begin{array}{l}.76 \\
.84\end{array}$ & $\begin{array}{l}.985 \\
.985\end{array}$ & $\begin{array}{l}1.30 \\
1.17\end{array}$ & $\begin{array}{l}145 \\
145\end{array}$ & None & $\cdots$ & -- & A1r & - & -- & -- & -- & Unt form & Subchannel Delta T \\
\hline Rapier & 26 & $\begin{array}{l}\text { b) Simulated } \\
\text { Ad jacent } \\
\text { Subchannels } \\
\text { (mixing through } \\
\text { rounded and } \\
\text { square throat) }\end{array}$ & $\mathrm{s} \leftrightarrow \mathrm{s}$ & 1.62 & $\begin{array}{c}1.82 \\
\text { to } \\
3.2\end{array}$ & $\begin{array}{c}1.12 \\
\text { to } \\
1.98\end{array}$ & 264 & None & -- & -- & Alr & $\cdots$ & $-\cdot$ & -- & -- & Unheated & $\begin{array}{l}\mathrm{NO}_{2} \text { Tracer Concen- } \\
\text { tration }\end{array}$ \\
\hline & & c) 5 in a row & $\begin{array}{l}\text { Across } \\
\text { gaps be- } \\
\text { tween } \\
\text { hemi- } \\
\text { spheres } \\
\text { and } \\
\text { rectangles }\end{array}$ & $\begin{array}{l}.76 \\
.84\end{array}$ & $\begin{array}{l}1.58 \\
1.58\end{array}$ & $\begin{array}{l}2.07 \\
1.88\end{array}$ & $\begin{array}{l}240 \\
240\end{array}$ & None & -- & -- & A1r & -- & -- & - & -- & Unheated & $\begin{array}{l}\mathrm{NO}_{2} \text { Tracer Concen- } \\
\text { tration }\end{array}$ \\
\hline
\end{tabular}


TABLE II (Continued)

\begin{tabular}{|c|c|c|c|c|c|c|c|c|c|c|c|c|c|c|c|c|c|}
\hline \multirow[b]{2}{*}{ Source } & \multirow[b]{2}{*}{$\begin{array}{l}\text { Ref. } \\
\text { No. }\end{array}$} & \multicolumn{6}{|c|}{ Test Geometry } & \multicolumn{3}{|c|}{ Spacers } & \multicolumn{6}{|c|}{ Flow Conditions } & \multirow{3}{*}{\begin{tabular}{l}
\multicolumn{1}{c}{$\begin{array}{c}\text { Experimental } \\
\text { Technique } \\
\text { (Quantity Measured) }\end{array}$} \\
$\mathrm{NO}_{2}$ Trocer Concen- \\
tration
\end{tabular}} \\
\hline & & Number of Rods & $\begin{array}{l}\text { Mixing } \\
\text { Array }\end{array}$ & $\begin{array}{l}\text { Diam. } \\
1 \mathrm{n} .\end{array}$ & $\begin{array}{l}\text { Pitch } \\
\text { in. }\end{array}$ & $\frac{\text { Pitch }}{\text { Diam. }}$ & $\begin{array}{l}L \\
\text { In. }\end{array}$ & Type & $\begin{array}{c}\text { Bffective } \\
\text { Directional } \\
\text { Configuration }\end{array}$ & $\begin{array}{l}\text { Pitch } \\
\text { in. }\end{array}$ & Fluid & $\underset{\mathrm{F}}{\substack{\text { Temp. } \\
\mathrm{F}}}$ & $\begin{array}{l}\text { Press. } \\
\text { Avg. } \\
\text { psia }\end{array}$ & \begin{tabular}{|r|} 
Mass \\
Flux \\
$1 \mathrm{~b} /$ \\
$\mathrm{h}-\mathrm{ft}^{2}$ \\
$\times \quad 10^{-6}$ \\
\end{tabular} & $\begin{array}{r}\operatorname{Re} \\
\times \quad 10^{-3} \\
\end{array}$ & $\begin{array}{c}\text { Radial Heat } \\
\text { D1stribut1on } * *\end{array}$ & \\
\hline Elckhoff & 33 & $\begin{array}{l}\text { PFR Prototype } \\
\text { Bund1e }\end{array}$ & -- & -- & -- & -- & -- & Grids & None & 2 & Aitr & $80(?)$ & $15(?)$ & -- & $\cdots$ & Unheated & \\
\hline $\begin{array}{l}\text { Pekrul } \\
\& \\
\text { Cassidy }\end{array}$ & 30 & 2. & $T \leftrightarrow T$ & .512 & .652 & 1.27 & 45 & $\begin{array}{l}\text { Fins }-12 \text { on } \\
\text { each rod } \\
.066^{\prime \prime} \text { high }\end{array}$ & $\begin{array}{l}\text { Opposing } \\
\text { (.008" gap } \\
\text { between fins) }\end{array}$ & 48 & Water & 70 & $15(?)$ & $\cdots$ & $\cdots$ & Unheated & $\begin{array}{l}\text { Noise Analysis } \\
\text { Methods. 1) Resis- } \\
\text { tance. 2) Cross cor- } \\
\text { relation of conduct- } \\
\text { Ing noise signals }\end{array}$ \\
\hline $\begin{array}{l}\text { Felten } \\
\text { Cassidy \& } \\
\text { Dodd }\end{array}$ & 31 & 10 & $\mathrm{I} \longleftrightarrow \mathrm{T}$ & .512 & .650 & 1.27 & 49 & $\begin{array}{l}\text { Fins- } 12 \text { on } \\
\text { each rod } \\
.065^{\prime \prime} \text { high }\end{array}$ & $\begin{array}{l}\text { Opposing } \\
\text { (.008" gap } \\
\text { between fins) }\end{array}$ & 48 & Water & 120 & $15(?)$ & -- & -- & Unheated & $\begin{array}{l}\text { Nolse Analysis - } \\
\text { Resistence }\end{array}$ \\
\hline $\begin{array}{l}\text { Menze1 } \\
\& \\
\text { Brindley }\end{array}$ & 32 & 37 & $\mathrm{~T} \longleftrightarrow \mathrm{T}$ & $\mid \begin{array}{c}.517 \\
\text { and } \\
.312 \\
6 \text { rods }\end{array}$ & .679 & 1.31 & 43 & $\begin{array}{l}\text { Fins-12 on } \\
\text { each rod } \\
076 \text { " high } \\
\end{array}$ & $\begin{array}{l}\text { Opposing } \\
\text { (.010" gap } \\
\text { between fins) }\end{array}$ & 48 & Water & $\begin{array}{r}70 \\
\text { and } \\
170\end{array}$ & $15(?)$ & $\cdots$ & -- & Unheated & Dye Injection \\
\hline Bump & 34 & 91 & $\mathrm{~T} \leftrightarrow \mathrm{T}$ & .174 & .223 & 1.28 & 17.4 & $\begin{array}{l}\text { W1 re wrap } \\
\text { on each rod } \\
-.049^{\prime \prime} \\
\text { high }\end{array}$ & Confluent & 6 & Water & -- & -- & -- & 72 & Unheated & Dye Injection \\
\hline
\end{tabular}

LEGEND: T - Triangular subchanneI

$S$ - Square Subchanne1

-. - Unspecified

*

-All heated cases were uniformly axial heated. 
Codes for Subchannel Analysis

\begin{tabular}{|c|c|c|c|c|c|c|c|}
\hline \multirow[b]{2}{*}{ Author } & \multirow[b]{2}{*}{ Code } & \multirow[b]{2}{*}{ Reference } & \multicolumn{2}{|c|}{ Natural Mixing } & \multicolumn{2}{|c|}{ Forced Mixing } & \multirow[b]{2}{*}{$\begin{array}{l}\text { Molecular } \\
\text { Conduction }\end{array}$} \\
\hline & & & $\begin{array}{c}\text { Turbulent } \\
\text { Interchange }\end{array}$ & $\begin{array}{l}\text { Diversion } \\
\text { Cross-flow }\end{array}$ & $\begin{array}{c}\text { Flow } \\
\text { Scattering }\end{array}$ & $\begin{array}{c}\text { Flow } \\
\text { Sweeping }\end{array}$ & \\
\hline Kattchee \& Reynolds & HECTIC-II & 36 & B & NC & NC & NC & NC \\
\hline Armour and Smith & MANTA & 37 & B & NC & NC & NC & $\mathbf{A}$ \\
\hline Lowe & (None) & 38 & B & NC & NC & NC & NC \\
\hline Schramm \& Berland & AI & 39 & NC & A & NC & NC & NC \\
\hline oldaker & $G-20$ & 40 & NC & NC & NC & B & חצ \\
\hline Sanders & $\begin{array}{c}\text { U-3 } \\
\text { Modified }\end{array}$ & 41 & NC & NC & NC & B & NC \\
\hline Schraub & MIXER & 43 & B & NC & B & NC & NC \\
\hline Zerilick, et al. & $\begin{array}{l}\text { THINC } \\
\text { THINC-II }\end{array}$ & 42 & $\begin{array}{l}\text { A } \\
\text { A }\end{array}$ & $\begin{array}{l}\mathrm{A} \\
\mathrm{NC}\end{array}$ & $\begin{array}{c}\mathrm{NC} \\
\mathrm{B}\end{array}$ & $\begin{array}{c}\text { NC } \\
*\end{array}$ & $\begin{array}{c}\text { NC } \\
*\end{array}$ \\
\hline Rowe & COBRA & 13 & B & B & NC & NC & NC \\
\hline St. Pierre & SASS & 11 & $\mathbf{A}$ & A & NC & NC & NC \\
\hline Bowring & HAMBO & 3 & B & $\mathbf{A}$ & B & B & NC \\
\hline
\end{tabular}

LEGEND: A - Model Predicts or Code Calculates

B - Same as A but Empirical Data Provided as Program Input

NC - Not Considered

* - Not Published 
TABLE IV

Subassembly Geometries Typical of

Liquid Metal Fast Breeder Reactors,

Heavy Water, and Light Water Reactor Designs

\begin{tabular}{|c|c|c|c|c|c|}
\hline & Spacer Method & Rod Array & $\begin{array}{c}\text { Rod } \\
\text { Diameter } \\
\text { (inches) }\end{array}$ & $\begin{array}{l}\text { Rod to Rod } \\
\text { Spacing } \\
\text { (inches) }\end{array}$ & $\begin{array}{l}\text { Pitch } \\
\text { Diameter }\end{array}$ \\
\hline LMFBR & $\begin{array}{l}\text { Wire Wrap or } \\
\text { Grid }\end{array}$ & $\begin{array}{l}\text { Triangular } \\
\text { or Square }\end{array}$ & $.2-.3$ & $.030-.065$ & 1.18 \\
\hline CANADIAN BLW & Wart-type & Triangular & $.7-.8$ & .040 & 1.05 \\
\hline US PWR & Grid & Square & $.4-.5$ & $.130-.150$ & 1.31 \\
\hline US BWR & Grid & Square & $.5-.6$ & $.160-.180$ & 1.33 \\
\hline
\end{tabular}


TABLE V

Mixing Studies - Proposed or in Progress

Part A

For Water Cooled Reactor Application

\begin{tabular}{|c|c|c|c|c|c|c|c|c|c|c|}
\hline & \multicolumn{4}{|c|}{ Geometry } & \multicolumn{6}{|c|}{ Test Conditions } \\
\hline & \multirow[b]{2}{*}{ Geometry } & \multirow[b]{2}{*}{ Rod Spacing Method } & \multirow{2}{*}{$\begin{array}{c}\text { Rod Spacing } \\
\text { (inches) }\end{array}$} & \multirow{2}{*}{$\begin{array}{c}\text { Rod } \\
\text { Diameter } \\
\text { (inches) } \\
\end{array}$} & \multicolumn{2}{|c|}{ Power Distribution } & \multirow{3}{*}{$\begin{array}{l}\begin{array}{c}\text { Pressures } \\
\text { (psia) }\end{array} \\
500,750, \\
1000,1200\end{array}$} & \multirow{3}{*}{$\begin{array}{l}\text { Inlet } \\
\text { Temp. } \\
\text { (F) } \\
360, \\
400, \\
450, \\
500\end{array}$} & \multirow{3}{*}{ 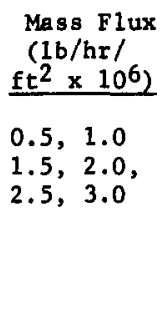 } & \multirow{2}{*}{$\begin{array}{l}\text { Average Outlet } \\
\text { Quality }(\%)\end{array}$} \\
\hline & & & & & Radial & Axtal & & & & \\
\hline \multirow[t]{2}{*}{ Columbia (a) } & $\begin{array}{l}\text { 19-rod triangu- } \\
\text { lar array in } \\
4.068^{\prime \prime} \text { ID flow } \\
\text { tube }\end{array}$ & $\begin{array}{l}\text { Rod to rod spacers . } 125^{\prime \prime} \\
\text { wide, . 31" long every 9" } \\
\text { axially } \\
\text { Rod to wall spacers .125" } \\
\text { wide, .31" long every } 4.5 " \\
\text { axially }\end{array}$ & .040 rod to rod & .780 & $\begin{array}{l}\text { Outer ring } \\
100 \% \\
\text { Intermediate } \\
\text { ring } 71.5 \% \\
\text { Center rod } \\
69.4 \%\end{array}$ & Uniform & & & & Subcooled to 30 \\
\hline & $\begin{array}{l}20 \text {-rod square } \\
\text { array, } 4 \times 5\end{array}$ & $\begin{array}{l}\text { Grid spacers every } 15^{\prime \prime} \\
\text { axially }\end{array}$ & $.133 \mathrm{rod}$ to $\mathrm{rod}$ & .422 & $\begin{array}{l}8 \text { rods, } 100 \% \\
12 \text { rods, } 86 \%\end{array}$ & Uniform & $\begin{array}{l}500,750 \\
1000,1200\end{array}$ & $\begin{array}{l}360 \\
400 \\
450 \\
500\end{array}$ & $\begin{array}{l}1.0,2.0 \\
3.0\end{array}$ & Subcooled to 30 \\
\hline PNL & $\begin{array}{l}\text { Stimulated ad- } \\
\text { jacent channels } \\
\text { in square array }\end{array}$ & $\begin{array}{l}\text { Pads at throat .125'wide, } \\
.5^{\prime} \text { long every } 8^{\prime \prime} \text { axially }\end{array}$ & $\begin{array}{l}.020 \text { and } .080 \text { rod } \\
\text { to rod }\end{array}$ & .564 & Uniform & Uniform & 400,750 & $\begin{array}{l}420 \\
490\end{array}$ & $\begin{array}{l}1.0,2.0 \\
3.0\end{array}$ & $0-30$ \\
\hline
\end{tabular}

Continued 
TABLE V, Part A (Continued)

\begin{tabular}{|c|c|c|c|c|c|c|c|c|c|c|}
\hline & \multicolumn{4}{|c|}{ Geometry } & \multicolumn{6}{|c|}{ Test Conditions } \\
\hline & Geometry & Rod Spacing Method & $\begin{array}{l}\text { Rod Spac1ng } \\
\text { (1nches) }\end{array}$ & $\begin{array}{c}\text { Rod } \\
\text { Diameter } \\
\text { (inches) }\end{array}$ & $\begin{array}{c}\text { Power Distr: } \\
\text { Radial } \\
\end{array}$ & $\frac{1 \text { bution }}{\text { Axtal }}$ & $\begin{array}{l}\text { Pressures } \\
\text { (poia) }\end{array}$ & $\begin{array}{l}\text { Inlet } \\
\text { Temp. } \\
\text { (E) }\end{array}$ & $\begin{array}{r}\text { Mags Flux } \\
(1 \mathrm{~b} / \mathrm{hr} / \\
\left.\mathrm{ft} \mathrm{t}^{2} \times 10^{6}\right) \\
\end{array}$ & $\begin{array}{l}\text { Average Outlet } \\
\text { Quality }(\%)\end{array}$ \\
\hline \multirow[t]{4}{*}{$\underset{(\mathrm{CRNL})}{\mathrm{AECL}-}$} & $\begin{array}{l}\text { Rectangular ele- } \\
\text { ment } 800 \times 1.60 \\
\text { Inches wide }\end{array}$ & $\begin{array}{l}\text { Removable dividing strip } \\
\text {.125" wide at center to } \\
\text { form two subchannels. } \\
\text { slits provided in strip } \\
\text { for interchannel communi- } \\
\text { cation. }\end{array}$ & $\begin{array}{l}\text { slot width } .040,100 \\
\text { slot length } 4,6,12\end{array}$ & - & Unheated & - & 50 & Room & .01 to .25 & $\begin{array}{l}20-80 \text { (air } \\
\text { water) }\end{array}$ \\
\hline & I" diameter tube & $\begin{array}{l}\text { Internal test section } \\
\text { providing varying slot } \\
\text { length and slot width }\end{array}$ & $\begin{array}{l}\text { slot width } .012, \\
.040, .080 . \quad \text { Slot } \\
\text { length } 1.67,4,6\end{array}$ & - & Unheated & - & 50 & 70 & .2 to .7 & $\begin{array}{l}20-80 \text { (air } \\
\text { water) }\end{array}$ \\
\hline & $\begin{array}{l}\text { Two subchannel } \\
\text { system in trian- } \\
\text { gular array }\end{array}$ & Dividing strip & $\begin{array}{l}.040 \text { rod to rod } \\
\text { length } 12 \text { to } 18\end{array}$ & .780 & Unheated & - & 50 & Room & .01 to .25 & $\begin{array}{l}10-80 \text { (air } \\
\text { water) }\end{array}$ \\
\hline & $\begin{array}{l}\text { Two subchannel } \\
\text { system in trian- } \\
\text { gular array (com- } \\
\text { parable to PNL } \\
\text { tests of } \operatorname{Ref} .19 \text { ) }\end{array}$ & Dividing strip & $\begin{array}{l}.020, .040, .080 \\
\text { rod to rod } \\
1 \text { ength } 18,60\end{array}$ & .780 & Untform & Uni form & 150 & $\begin{array}{l}\text { To be } \\
\text { scaled } \\
\text { from } \\
\text { PNL ex } \\
\text { peri- } \\
\text { ments }\end{array}$ & .1 to 2 & $0-.60$ (Freon) \\
\hline GE $(P A-44)$ & $\begin{array}{l}9 \text { rod square } \\
\text { arrays }(3 \times 3)\end{array}$ & $\begin{array}{l}\text { a) 1/8" diameter pins } \\
\text { every } 90^{\circ} \text { circum., } \\
\text { every 12" axially } \\
\text { b) grid type spacer } \\
\text { every 19" axia11y }\end{array}$ & $\begin{array}{l}.168 \text { rod to rod } \\
.135 \text { rod to wall }\end{array}$ & .570 & $\begin{array}{l}\text { Uniform and } \\
3 \text { rods in } \\
\text { row heated }\end{array}$ & Unt form & 1000 & $\begin{array}{l}350 \\
525\end{array}$ & .25 to 1.5 & $\begin{array}{l}\text { Slightly sub- } \\
\text { cooled to } 50\end{array}$ \\
\hline
\end{tabular}


TABLE V

Mixing Studies - Proposed or in Progress

Part B

For Liquid Metal Cooled Reactor Application

\begin{tabular}{|c|c|c|c|c|c|c|c|c|c|c|}
\hline & \multicolumn{4}{|c|}{ Geometry } & \multicolumn{6}{|c|}{ Test Conditions } \\
\hline & \multirow{3}{*}{$\begin{array}{l}\text { Geometry } \\
\text { Simulated adja- } \\
\text { cent channels in } \\
\text { triangular array } \\
\text { (two test sec- } \\
\text { tions } 1 \mathrm{X} \text { and } 4 \mathrm{X} \\
\text { prototypic } \\
\text { geometry) }\end{array}$} & \multirow[b]{2}{*}{ Rod Spacing Method } & \multirow{2}{*}{$\begin{array}{c}\text { Rod Spacing } \\
\text { (inches) }\end{array}$} & \multirow{3}{*}{$\begin{array}{c}\begin{array}{c}\text { Rod } \\
\text { Diameter } \\
\text { (Inches) }\end{array} \\
\begin{array}{c}.25 \\
1.0\end{array}\end{array}$} & \multicolumn{2}{|c|}{ Power Distribution } & \multirow{3}{*}{$\begin{array}{c}\begin{array}{c}\text { Pressures } \\
\text { (psia) }\end{array} \\
15\end{array}$} & \multirow{3}{*}{ 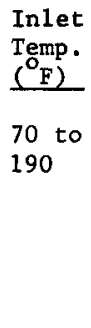 } & \multirow{3}{*}{$\begin{array}{l}\text { Mass Flux } \\
\begin{array}{l}\mathrm{b} / \mathrm{hr} / \\
\left.\mathrm{ft}{ }^{2} \times 10^{6}\right)\end{array} \\
.8 \text { to } 16.0 \\
.6 \text { to } 12.0\end{array}$} & \multirow{3}{*}{$\begin{array}{l}\text { Average Outlet } \\
\text { Quality }(\%) \\
\text { Unheated }\end{array}$} \\
\hline & & & & & Radia 1 & Axia 1 & & & & \\
\hline$\underset{\text { (FFTF) }}{\text { PNL }}$ & & $\begin{array}{l}\text { End plate only, no inter- } \\
\text { mediate spacers }\end{array}$ & $\begin{array}{l}.040 \text { rod to rod } \\
.120 \text { rod to rod }\end{array}$ & & Unheated & Unheated & & & & \\
\hline \multirow[t]{2}{*}{ (b) } & $\begin{array}{l}217 \text { pin trian- } \\
\text { gular array }\end{array}$ & Wire, 12 " pitch & $\begin{array}{l}.040 \text { rod to rod } \\
.040 \text { rod to wal1 } \\
\end{array}$ & .25 & Unheated & Unheated & 15 & $\begin{array}{l}70 \text { to } \\
190\end{array}$ & .5 to 9.0 & Unhea ted \\
\hline & $\begin{array}{l}37 \text { pin trian- } \\
\text { gular array } \\
\text { (normal configu- } \\
\text { ration \& pre-set } \\
\text { pin distortions) }\end{array}$ & Wire, 12" pitch & $\begin{array}{l}.040 \text { rod to rod } \\
\text { (norma } 1)\end{array}$ & .25 & Unheated & Unheated & 15 & $\begin{array}{l}70 \text { to } \\
190\end{array}$ & .5 to 9.0 & Unheated \\
\hline GE $(P \neq-10)$ & $\begin{array}{l}7 \text { pin triangular } \\
\text { array - 6x proto- } \\
\text { typic LMFBR geo- } \\
\text { metry (velocity } \\
\text { profiles only) }\end{array}$ & $\begin{array}{l}\text { End plate on1y, no in- } \\
\text { termediate spacers }\end{array}$ & $\begin{array}{l}.15-.45 \text { rod to rod } \\
.15-.45 \text { rod to wall }\end{array}$ & 1.5 & Unheated & Unheated & 15 & $\begin{array}{l}\text { Room } \\
\text { temp. }\end{array}$ & .9 to 3.2 & Unheated \\
\hline
\end{tabular}


CROSS-SECTION OF TYPICAL 19 ELEMENT BUNDLES IN CIRCULAR + HEXAGONAL FLOW DUCTS
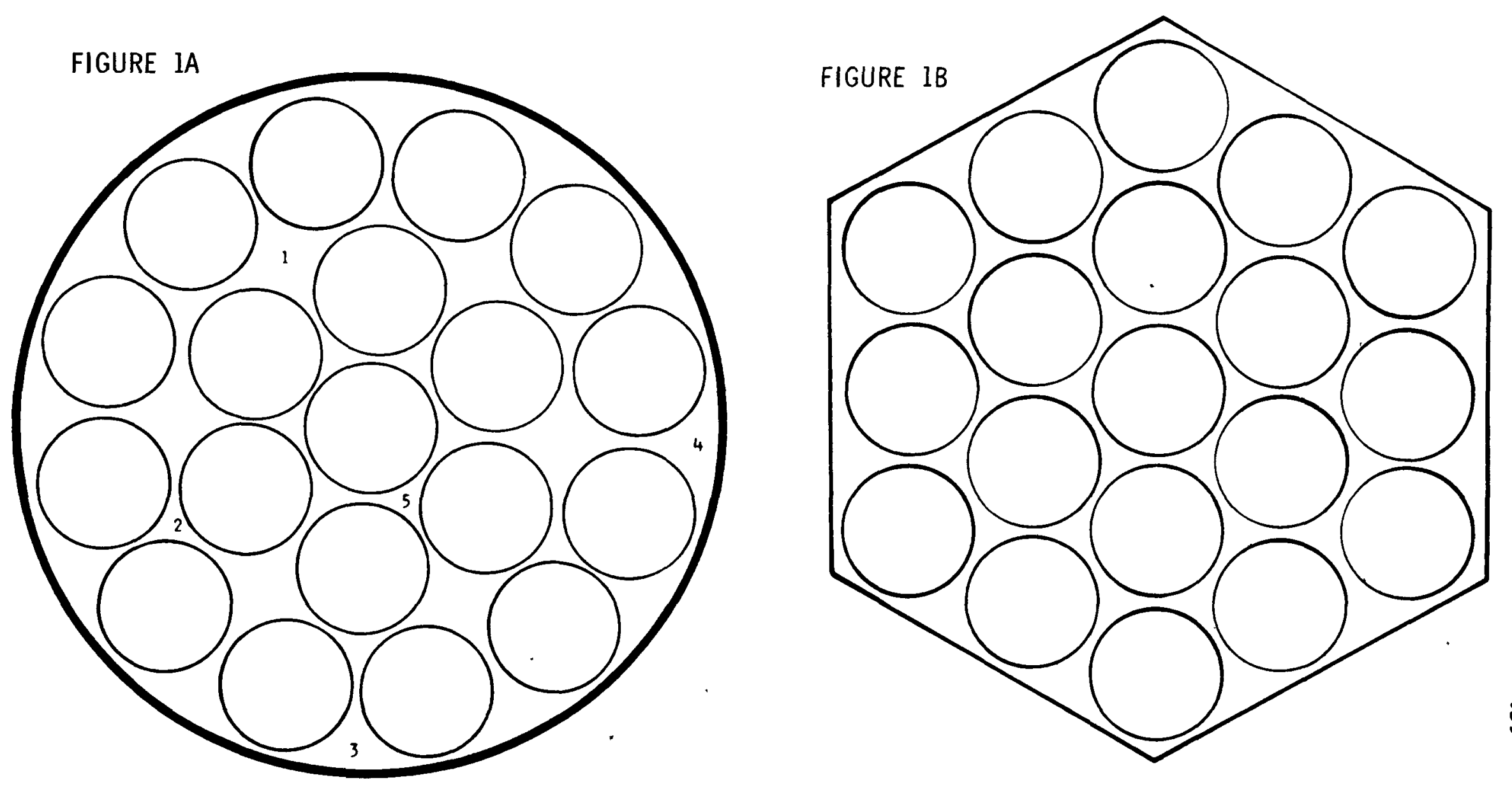
FIGURE 2. EFFECT OF NATURAL MIXING ON COOLANT TEMPERATURE

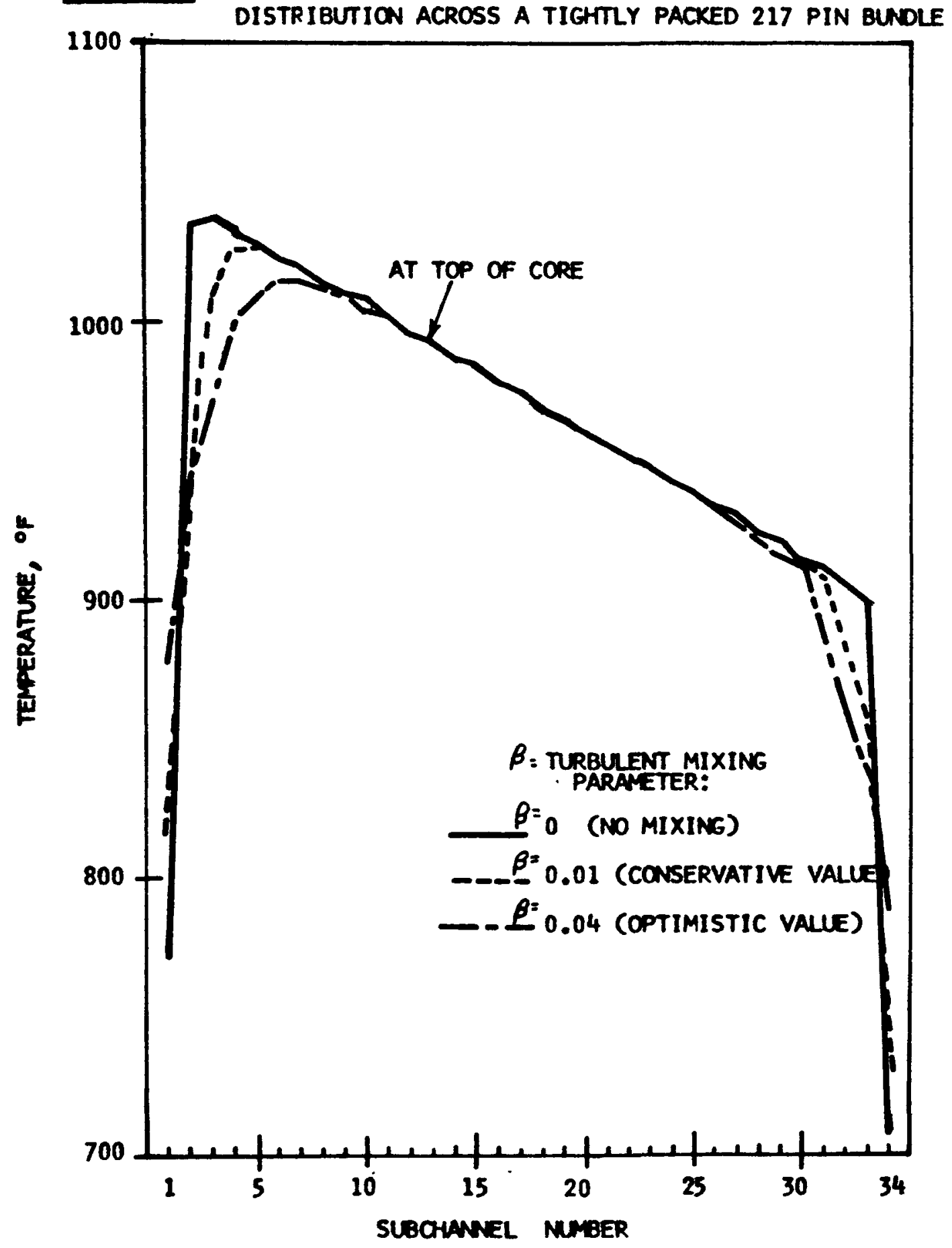


EFFECT OF NATURAL MIXING ON COOLANT TEMPERATURES FOR PIN MISALIGNENT IN A TIGHTLY PACKED BUNDLE.

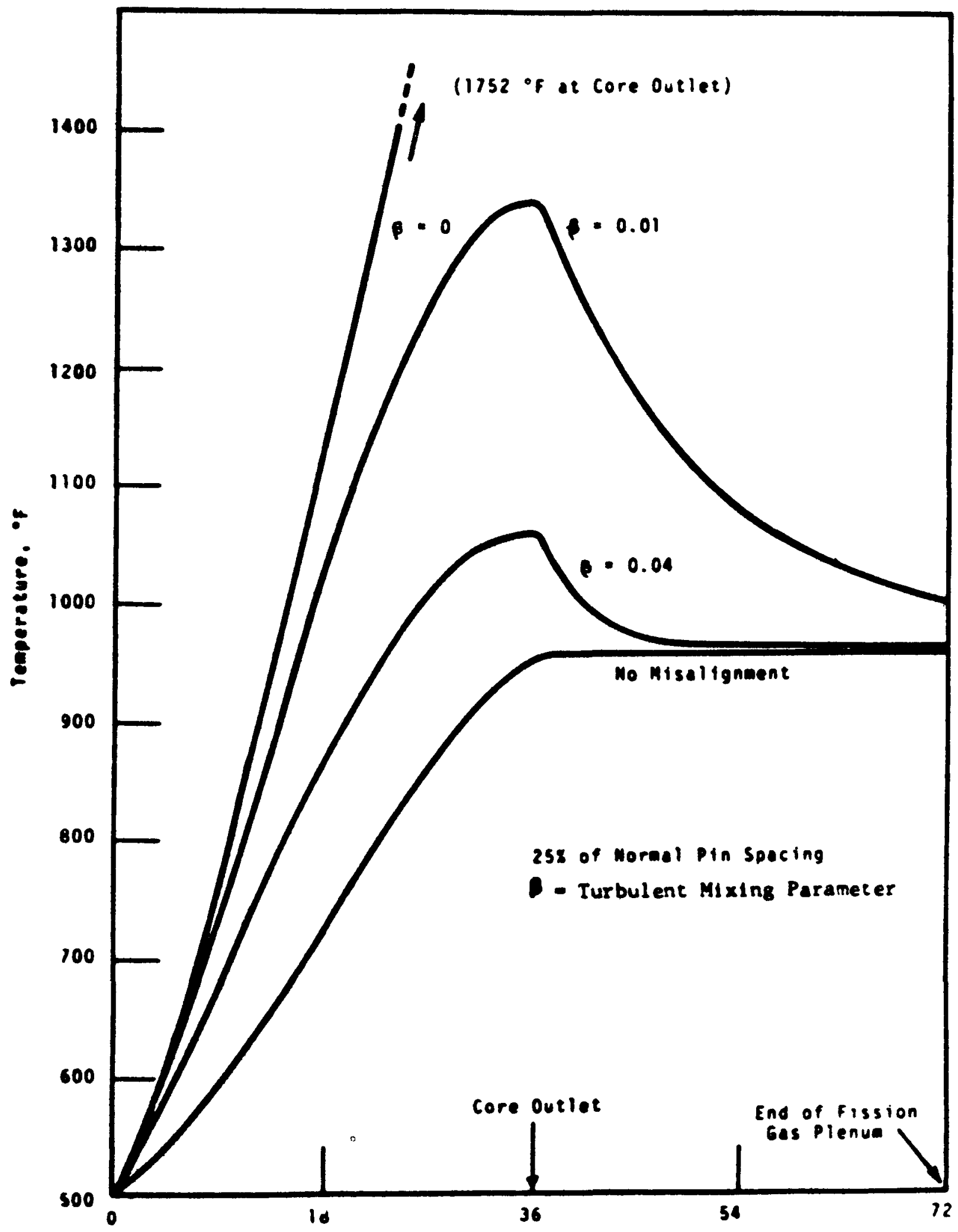


Figure 4 $\frac{\text { CROSS SECTION OF TWO CONNECTED SUBCHANNELS }}{\text { IN A TRIANGULAR ARRAY }}$

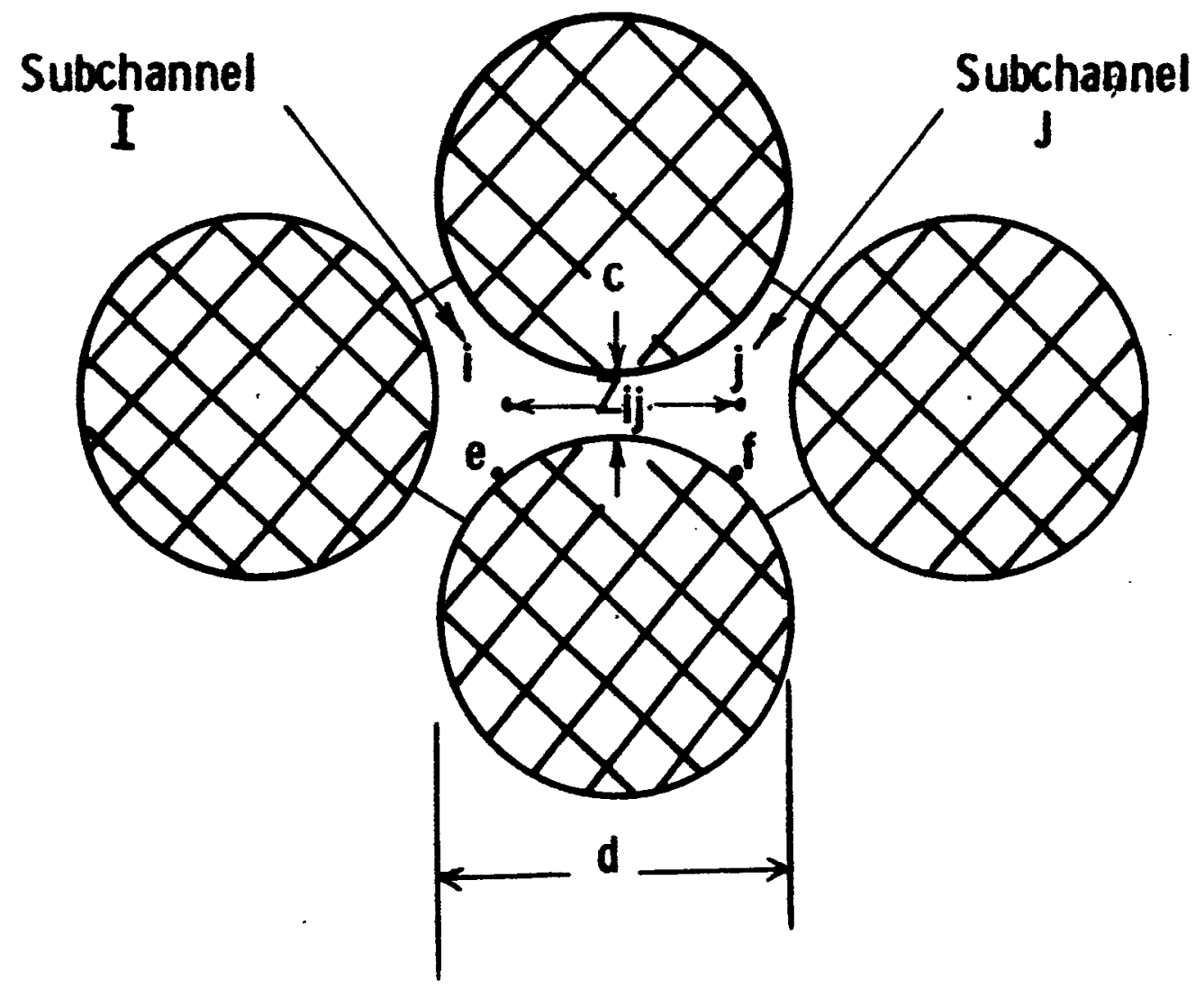




\section{REFERENCES}

1. Coates, D. E., "Inter-Channel Mixing and Coolant Temperature Distribution in Seven and Nineteen-Element Fuel Bundles Literature Survey," CGE Report X07-10001R, November 1960.

2. Moyer, C. B., "Coolant Mixing in Multi-rod Fuel Bundles," Riso Report No. 125, July 1964 (Issued 1966).

3. Bowring, R. W., "HAMBO, A Computer Programme for the Subchannel Analysis of the Hydraulic and Burnout Characteristics of Rod-Clusters, Part I: General Description," AEEW-R524, Apri1 1967.

4. Tong, L. S., Chelemer, H., and McCabe, Jr., E, "Hot Channel Factors for Flow Distribution and Mixing in Core Thermal Design," WCAP-2211, February 1963.

5. Leipunskii, A. I., et al., "The BN-350 and BOR Fast Reactors," Paper 3/1, London Conference on Fast Breeder Reactors, May 1966.

6. Leipunskii, A. I., et al., "Nuclear Power Plant BN-350," Detroit Meeting on Fast Reactor Technology, Supplement to ANS-100, April 1965.

7. Personal Communication with R. Peterson and A. Padilla, BNWL, January 1968 .

8. Grillo, P. and Testa, G., "Peak Heat-Flux Factor Dependence Upon Fuel Element Fabrication Parameters," Transactions of ANS, Volume 10, No. 2, November 1967.

9. Bender, D. J., Switick, D. M., and Field, J. H., "Turbulent Velocity Distribution in a Rod Bundle," GEAP-5411, October 1967.

10. "23rd Quarterly Report of the PA-10 Program," GEAP-5522, August 1967.

11. St. Pierre, Carl C., "SASS Code I - Subchannel Analysis for the Steady State," APPE-41, September 1966.

12. Rogers, J. T., and Tarasuk, W. R., "Natural Mixing of Coolant in Close-packed Nuclear Reactor Fuel Bundles," Proceedings of Canadian Congress of Applied Mechanics, May 1967 (also, CGE Report R64CAP29-I, July 1966).

13. Rowe, D. S., "Cross-Flow Mixing Between Parallel Flow Channels During Boiling, Part I: COBRA - Computer Program for Coolant Boiling in Rod Arrays," BNWL-371, Part 1, March 1967. 
REFERENCES (Continued)

14. Collins, R. D. and France, J., "Mixing of Coolant in Channels Between Close Packed Fuel Elements," IGR-TN/CA-847, January 1958.

15. Be11, W. H., and Letourneau, B. W., "Experimental Measurements of Mixing in Parallel Flow Rod Bundles," WAPD-TH-381, 1958.

16. Bishop, A. A., et a1., "Thermal and Hydraulic Design of CVTR Fuel Assemblies," CVNA-115, June 1962; and Sandberg, R. 0., and Bishop, A. A., "CVTR Thermal-Hydraulic Design for 65 MW Gross Fission Power," February 1965.

17. Nelson, P. A., et al., "Mixing in Flow Parallel to Rods Having a Square Lattice," WCAP-1607, July 1960.

18. Waters, E. D., "Fluid Mixing Experiments with a Wire Wrapped 7-Rod Bundle Fuel Assembly," HW-70178, August 1961 (Revised November 1963).

19. Rowe, D. S., and Angle, C. W., "Cross-Flow Mixing Between Parallel Flow Channels During Boiling, Part II: Measurement of Flow and Enthalpy in Two Parallel Channels," BNWL-371, Part 2, December 1967.

20. Rogers, J. T., and Tarasuk, W. R., "A Generalized Correlation for Natural Mixing of Coolant in Fuel Bundles," Transactions of American Nuclear Society, Vo1. 11, No. 1, June 1968.

21. Biggs, W. M., and Rust, J. H., "A Study of Interchannel Mixing Employing Activation Analysis," Transactions of American Nuclear Society, Vo1. 10, No. 2, November 1967.

22. Dean, R. A., "Coolant Mixing in Open Lattice Reactor Core," WCAP-3735, August 1963.

23. Clarke, G. J., "Mixing Studies of Types C19A14B, C19A14C, and C19X8D Fuel Bundles," TDVI-19, February 1961

24. Eifler, W., and Nijsing, R., "Fundamental Studies of Fluid Flow and Heat Transfer in Fuel Element Geometries, II. Experimental Investigation of Velocity Distribution and Flow Resistance in a Triangular Array of Parallel Rods," EUR 2193.e, February 1965.

25. Technological University of Eindhoven, "Final Report on the Research Program on the Heat Transfer and Fluid Flow Characteristic of a Pressurized Water Reactor," Report WW015-R128, December 1967.

26. Rapier, A. C., "Turbulent Mixing in a Fluid Flowing in a Passage of Constant Cross Section," TRG Report 1417(W), February 1967. 
REFERENCES (Continued)

27. Shimazaki, T. T., and Freede, W. J., "Heat Transfer and Hydraulic Characteristics of the SRE Fuel Element," TID-7529, Part I, Book 1, 1957.

28. McNown, J. S., et a1., "Tests on Models of Nuclear Reactor Elements, II. Studies on Diffusion," University of Michigan, AECU-3735 (Part II), March 1957.

29. Howieson, J., and McPherson, G. D., "Coolant Mixing in 19-Element Fuel Bundles," TDSI-31, July 1961.

30. Pekru1, P. J., and Cassidy, R. B., "HWOCR Dual Channel Cross-Flow Studies," AI-CE-TRD-1038, May 1966.

31. Felten, L. D., et a1., "HWOCR Multichannel Cross-Flow Studies," AI-CE-TDR-1089, November 1966.

32. Lenze1, G., and Brindley, J. H., "Coolant Mixing Tests for 37-Rod ETOCR-Type Bundles," AI-CE-MEMD-61, June 1967.

33. Eickhoff, K. G., et a1., "Engineering Development for Sodium Systems," Paper 5B/5, BNES London Conference on Fast Breeder Reactors, May 1966.

34. Bump, T. R., "Coolant Mixing in Fuel Subassemblies," Transactions of the American Nuclear Society, Vo1. 9, No. 2, November 1966.

35. "Flow Distribution and Three-Scale Prototype of SEFOR Fuel Bundle," GEAP-5184, 1966.

36. Rattchee, N., and Reynolds, W. C., "HECTIC-II, An IBM 7090 Fortran Computer Program for Heat Transfer Analysis of Gas or Liquid Coolant Reactor Passages," IDO-28595, December 1962 (Revised December 1965).

37. Armour, S. F., and Smith, D. L., "MANTA - Mixing Analyzed Noda1 Thermal-Hydraulic Analyses," GEAP-4805, February 1965.

38. Lowe, P. A., "A Two-Dimensional Turbulent Flow Mixing Mode1 for Parallel Flow Rod Bundles," ANS Transactions, Vol. 10, No. 1, June 1967.

39. Schramm, D. E., and Berland, R. F., "A Multi-Channel, Two-Dimensional Phase Flow Model and IBM 7090 Code," NAA-SR-TDR-9444, December 1963.

40. Oldaker, I. E., "Sheath Temperatures. A G-20 Computer Program for Fuel Bundles," AECL-2269, May 1965. 
REFGERENCES (Continued)

41. Sanders, J. P., "The Modified U-3 Code: A Thermal-Hydraulic Code for Axial Flow with Mixing in Fuel Bundles," ORNL-4016, November 1966.

42. Zernick, W., Currin, H. B., Elyash, E., and Previti, G., "'THINC' A Thermal Hydrodynamic Interaction Code for a Semi-Open or Closed Channel Core," WCAP-3704, February 1962.

43. Personal communication with F. Schraub, March 1968.

44. Dwyer, O. E., "Recent Developments in Liquid-Metal Heat Transfer," Atomic Energy Review, Vol. IV, No. 1, IAEA, Vienna, 1966. 